\title{
PROCESOS DE CONFLICTIVIDAD LABORAL EN EL MARCO DE LA PANDEMIA DEL COVID-19 EN ARGENTINA (MARZO- MAYO 2020) ${ }^{1}$
}

\author{
VICTORIA BASUALDO ${ }^{2}$ \\ PABLO PELÁEZ 3
}

RESUMEN: Este artículo tiene por objetivo contribuir al análisis de algunos de los procesos de conflictividad laboral, que se produjeron en contrapunto con diversas políticas empresariales, focalizándose específicamente en los dos primeros meses de vigencia de las políticas de aislamiento obligatorio aplicadas en Argentina por la pandemia del COVID-19, a partir del 20 de marzo de 2020. En primer lugar se presenta un breve análisis de la situación laboral previa a la pandemia, teniendo en cuenta el estado de relaciones laborales al comienzo del nuevo gobierno y los desafíos en varios planos. En segundo lugar, se analizan los condicionamientos que implicó la política de aislamiento en términos de la actividad económica y laboral, y las formas en que esta política de protección sanitaria impactó en las relaciones laborales en diversos sectores. En tercer lugar, y como núcleo central del trabajo, se realiza una aproximación tentativa y preliminar a los procesos de conflictividad laboral desarrollados desde el 20 de marzo hasta fines de mayo de 2020. Reconociendo numerosos desafíos conceptuales, metodológicos y de fuentes, este trabajo propone una primera aproximación a las distintas etapas, abordando las diversas actividades económicas, con foco en el Área Metropolitana de Buenos Aires (AMBA) pero refiriendo a procesos en otras

\footnotetext{
1 Este trabajo se realizó en el marco del PICT-2016-0575 “Transformaciones estructurales y relaciones laborales: cambios productivos y estrategias sindicales en la industria siderúrgica y azucarera desde mediados de los años 70 hasta la actualidad", en el marco del Área de Economía y Tecnología de FLACSO Argentina y el Programa "Estudios del trabajo, movimiento sindical y organización industrial". Agradecemos muy especialmente los comentarios y sugerencias a este trabajo de Eduardo Basualdo, Pablo Manzanelli, Alejandra Esponda, Silvia Nassif, Andrea Copani, Ricardo Spaltenberg, Guillermo Gianibelli y Julia Soul, así como al debate colectivo en el marco de eventos sindicales y académicos organizados desde los mencionados Área y Programa de FLACSO Argentina,en los que se discutió una versión preliminar del presente trabajo. Los posibles aportes del artículo están sin duda vinculados con estas contribuciones y discusiones, aunque por supuesto la forma final de este texto no es responsabilidad de ninguno de los/as comentaristas mencionados.

2 CIC CONICET- Área de Economía y Tecnología de FLACSO-IICSAL. Contato: basuvic@yahoo.com.ar, https://orcid.org/0000-0003-4150-9797.

3 Becario CONICET-Área de Economía y Tecnología de FLACSO-IICSAL Contato: pablojpel@gmail.com, https://orcid.org/0000-0001-6525-6259.
} 
regiones del país en los casos en que se dispuso de información. Este breve recorrido permite iluminar la existencia de diversas protestas y conflictos laborales, estrechamente vinculados con una serie de políticas empresariales que tuvieron como objetivo transferir, en la mayor medida posible, los costos de la crisis económica a otros sectores sociales, y especialmente, a la clase trabajadora.

Palabras clave: Pandemia COVID-19; Crisis económica; Conflictividad laboral; Políticas empresariales; Argentina.

ABSTRACT: This article purposes to contribute to the analysis of some labour struggle process that emerged to contrast to diverse company policies, in particular focused at the first months of obliged isolation policy period applied in Argentina in COVID 19 pandemic, from 20th March 2020. In the first place, it introduces a brief analysis of the work situation before the pandemic, consider the labour relations status in the beginning of the new government and its challenges in several plans. In second place, it analyses the determinants that implicate in isolation policy, in terms of economic and labour activities and which way this sanitary protection policy affected the working relations in several sectors. In third place, as the core of this work, have been made a trial and preliminary approximation to the labour struggles process developed since 20th March till the end of May of 2020. Recognising several conceptual, methodological and sources challenges, this work proposes a first approximation to the distinct stages, to approach several economic activities, focusing Buenos Aires Metropolitan Area (AMBA), but also referring to process in other regions of the country where information was available. This brief round allows enlighten the existence of diverse labour protests and struggles, connected to several company policies that had the aim to transfer, in the biggest measure possible, the economic crisis costs to other social sectors, and especially to the working class.

Keywords: Pandemic COVID-19; Economic crisis; Labour struggles; Company policies, Argentina.

\section{INTRODUCCIÓN}

Este artículo tiene por objetivo contribuir al análisis de algunos de los procesos de conflictividad laboral, que se produjeron en contrapunto con diversas políticas empresariales, focalizándose específicamente en los dos primeros meses de vigencia de las políticas de aislamiento obligatorio aplicadas en Argentina por la pandemia del COVID-19, a partir del 20 de marzo de 2020. En primer lugar se presentará un breve análisis de la situación laboral previa a la pandemia, teniendo en cuenta el estado de relaciones laborales al comienzo del nuevo gobierno y los 
desafíos en varios planos. En segundo lugar, se analizarán los condicionamientos que implicó la política de aislamiento en términos de la actividad económica y laboral, y las formas en que esta política de protección sanitaria impactó en las relaciones laborales en diversos sectores. En tercer lugar, y como núcleo central del trabajo, se realizará una aproximación tentativa y preliminar a los procesos de conflictividad laboral desarrollados desde el 20 de marzo hasta fines de mayo de 2020. Reconociendo numerosos desafíos conceptuales, metodológicos y de fuentes, este trabajo propone una primera aproximacióna las distintas etapas, abordando las diversas actividades económicas, con foco en el Área Metropolitana de Buenos Aires (AMBA) pero refiriendo a procesos en otras regiones del país en los casos en que se dispuso de información. Se parte aquí de informes realizados por diversas instituciones y organizaciones sobre impactos en las relaciones laborales y conflictos en esta etapa, y en la consulta de fuentes de prensa, documentos sindicales así como información provista por referentes de diversas actividades. En forma sintética y breve se abordan además las respuestas estatales a los procesos de conflictividad y las políticas públicas desarrolladas respecto de la cuestión laboral en este período, en función de su incidencia en los procesos de demanda y organización.

\section{El LEGADO DEL GOBIERNO DE MAURICIO MACRI (2015-9) EN TÉRMINOS DE RELACIONES LABORALES Y EL DESAFÍO ENFRENTADO POR EL NUEVO GOBIERNO ENTRE DICIEMBRE} 2019 Y EL 20 DE MARZO DE 2020.

El análisis de las relaciones laborales en la Argentina en el período seleccionado debe tener en cuenta en primer lugar el legado del gobierno de Mauricio Macri que introdujo desde diciembre de 2015 cambios significativos en la dirección de las políticas públicas, tomando a las relaciones laborales como un eje central. En un contexto de presentación de la etapa previa de gobierno como causante de una "pesada herencia", se produjo una reconfiguración regresiva de la intervención en áreas estratégicas referidas a derechos humanos, económicos, sociales y laborales que incluyeron despidos fuertes en el sector público, seguidos por la contratación de funcionarios propios con sueldos elevados. En términos económicos, se llevó adelante un cambio abrupto de las formas de intervención estatal en cuestiones estratégicas como los subsidios a los servicios públicos, con un correlato de subas de costos tanto de transporte como de servicios varios, liderados por los del gas, electricidad, y agua ${ }^{4}$. Se implementó una apertura comercial y una liberalización del mercado cambiario, con un correlato negativo significativo en el entramado productivo, lo que a su vez se tradujo en un incremento de despidos en el sector privado. Al mismo tiempo, se produjo a lo largo de todo el período un crecimiento exponencial del endeudamiento externo y

\footnotetext{
${ }^{4}$ CIFRA-CTA, "El incremento en las tarifas de servicios públicos y su peso sobre los salarios", enero 2019, disponible en: http://www.centrocifra.org.ar/publicacion.php?pid=137.
} 
fuga de capitales. ${ }^{5}$ Paralelamente, se llevó adelante un fuerte ajuste en el gasto estatal, despidos en sectores estratégicos y eliminación o des-jerarquización de dependencias públicas clave, incluyendo trabajo, cultura, salud y ciencia y tecnología. Contra las promesas electorales, se produjo una importante aceleración del proceso inflacionario y un progresivo retroceso de la participación de los/as asalariados/as en el ingreso.

Las relaciones laborales fueron un punto central de debate y la ofensiva en este campo no sólo incluyó campañas de desprestigio sobre diversos sindicalistas y sindicatos (siendo un caso paradigmático la persecución a dirigentes de organizaciones como el Sindicato Único de Trabajadores de la Educación (SUTEBA) y la Confederación de Trabajadores/as de la Educación de la República Argentina (CTERA), en el marco del conflicto llevado adelante por gremios docentes en todo el país), sino también una fuerte avanzada de cuestionamiento del campo del derecho laboral, atribuyendo a los abogados laboralistas y la defensa de los derechos de los/as trabajadores/as como un costo negativo para la sociedad en su conjunto, así como causante de un desaliento de la inversión. Otro aspecto significativo de retroceso en los derechos laborales fue la aprobación en febrero de 2017 de una reforma a la Ley de Riesgos del Trabajo, que introdujo cambios tan relevantes como la obligatoriedad del trabajador de atravesar una instancia administrativa previa a la judicial compuesta por comisiones médicas a las que los trabajadores deben acudir (las cuales tienen número reducido y dispersión territorial que dificulta su alcance). En este contexto tuvo lugar el impulso, a fines de 2017, por parte del gobierno de Mauricio Macri de tres proyectos en el ámbito legislativo que generaron una fuerte controversia: la Reforma previsional, la Reforma impositiva y la Reforma laboral. Mientras que las dos primeras fueron implementadas, aún en un contexto de movilización masiva y extenso repudio, la Reforma laboral, que incluía en su versión inicial cambios muy importantes como los "bancos de horas", la ampliación de la facultad del empleador de modificar condiciones de trabajo respecto de lo que se había pactado en el proceso de contratación original, y cambios muy significativos para des-responsabilizar a empresas en procesos de tercerización, nunca pudo ser implementada como tal debido a los niveles de movilización y oposición de trabajadores/as a lo largo de todo el período, y en jornadas históricas de movilización masiva como las del 14 y 18 de diciembre de 2017.

Sin embargo, diversos aspectos de esta reforma laboral fueron primero presentados como proyectos específicos durante 2018, al tiempo que se intentó su implementación por otros medios alternativos a los proyectos legislativos. Algunas de las formas de implementación“de hecho"se dieron a partir de la actualización de instancias de negociación colectiva que incorporaron cláusulas

${ }^{5}$ Eduardo Basualdo (editor), Mariano Barrera, Leandro Bona, Mariana González, Pablo Manzanelli y Andrés Wainer, Endeudar y fugar. Un análisis de la historia económica argentina de Martínez de Hoz a Macri, Buenos Aires: Siglo Veintiuno editores, 2020, Edición ampliada. 
flexibilizadoras, como el caso del convenio firmado por el Sindicato del Gas y Petróleo en el yacimiento de Vaca Muerta (Patagonia), el acuerdo de crisis entre la Asociación de Trabajadores de la Industria Láctea de la República Argentina (ATILRA) y la empresa Sancor o el convenio firmado entre la empresa Mercado Libre y la Unión de Trabajadores de Carga y Descarga (UTCD), y del otorgamiento de personería a sindicatos por empresa, como el de la Asociación Sindical de Trabajadores de la empresa FlyBondi. El alza inflacionaria tuvo consecuencias devastadoras sobre el poder adquisitivo de los salarios, tanto de trabajadores registrados como de no registrados. En un contexto en que el Ministerio de Trabajo fue convertido en Secretaría, se buscó obstaculizar de todas las maneras posibles el desarrollo tanto de la conflictividad como de la negociación colectiva, y en el marco de esta última, se presionó para introducir cláusulas flexibilizadoras y pérdida de derechos. En suma, en un contexto de pérdida de puestos de trabajo, ajuste estatal y crecimiento exponencial del endeudamiento externo, la evolución de las relaciones laborales fue sumamente regresiva en esta etapa y si no lo fue más fue por el muy alto grado de conflictividad sindical y movilización masiva que logró alcanzarse a lo largo del período, aún en un contexto totalmente adverso, y que sin duda fue clave para frenar los intentos más extremos de reforma laboral y condicionar y morigerar los procesos de ajuste. ${ }^{6}$

Por todos estos factores, los desafíos en materia laboral a comienzos del nuevo gobierno eran acuciantes. Los efectos de las políticas públicas desarrolladas entre 2015 y 2019 se sumaron a problemáticas de largo plazo, que incluyen la persistencia de niveles de trabajo no registrado de un tercio de la población económicamente activa, el avance y consolidación de la tercerización laboral en todo tipo de actividades económicas, con un correlato de diferenciación en los colectivos laborales, en términos salariales, de derechos y de organización sindical, y la expansión de distintas formas de precarización laboral a partir de formas "flexibles" de contratación en el ámbito público y privado que implicaron reducción o eliminación de derechos. Se sumaron además a un proceso de acelerado cambio tecnológico que implicó la transformación de las relaciones laborales de varios sectores, poniendo en jaque puestos de trabajo y condiciones laborales en diversos casos, así como la expansión de la economía de plataformas, basada en una negación explícita de la relación asalariada y en consecuencia la

\footnotetext{
${ }^{6}$ Victoria Basualdo, "Los intentos de Reforma Laboral regresiva en la Argentina desde 2015: una lectura en perspectiva histórica" en ClariceGontarskiSperanza (coord.), História do Trabalho: entre debates, caminhos e encruzilhadas, Brasil, Paco Editorial, 2020. Disponible en: https://lehmt.org/2020/05/23/livro-historia-do-trabalho-entre-debates-caminhos-e-encruzilhadasdownload-gratuito/
} 
total falta de derechos laborales. ${ }^{7}$ En los comienzos del gobierno de Alberto Fernández se revirtieron algunos de los cambios más regresivos de la etapa anterior. Las secretarías de Salud y Trabajo recuperaron su rango como ministerios, y se dio un cambio de rumbo en sectores claves como derechos humanos, así como un mayor énfasis en la importancia transversal de las dimensiones de género. Sin embargo, en un contexto de crisis de la deuda y paralización del gasto estatal, no se concretaron modificaciones sustantivas en las relaciones laborales entre diciembre y marzo, cuando se declaró la crisis por la pandemia del COVID-19.

\section{LA CRISIS DEL COVID-19 Y LOS MÚLTIPLES IMPACTOS EN LAS RELACIONES LABORALES}

El Poder Ejecutivo de Argentina, a diferencia de lo ocurrido en otros países de la región, tomó respecto de la pandemia decisiones tempranas y centralizadas, aplicables a todo el territorio nacional. El Decreto 297/2020 de Aislamiento Social, Preventivo y Obligatorio (ASPO) dispuso medidas de aislamiento y distanciamiento social que implicaron en primera instancia una cuarentena total en el territorio nacional desde el 20 de marzo como respuesta a la pandemia generada por el COVID-19, luego que fuera declarada por la Organización Mundial de la Salud (OMS), y cuando a esa fecha el país registraba 128 casos de contagiados/as y 3 fallecidos/as a nivel nacional desde el comienzo de la pandemia. El principal objetivo del decreto fue el resguardo del derecho a la salud pública de la población $\mathrm{y}$, al mismo tiempo, mitigar el impacto sanitario provocado por la pandemia. ${ }^{8}$ Esta decisión orientada a preservar el derecho a la vida y la salud, implicó en los hechos una serie de modificaciones sobre las condiciones de reproducción de la vida cotidiana de la población, de su trabajo y la organización familiar, así como de los procesos de producción, circulación y comercialización de la producción. El gobierno nacional fue determinando una serie de cambios en sucesivas etapas que implicaron en su inicio una distinción entre actividades esenciales y no esenciales para el funcionamiento social. En las

\footnotetext{
7 Victoria Basualdo (coord.), Hernán Letcher, Silvia Nassif, Mariano Barrera, Nayla Bosch, Andrea Copani, Pablo Peláez, Mauro Rojas, "Cambio tecnológico, tercerización laboral e impactos sobre el empleo. Desafíos desde y para una narrativa argentina", Buenos Aires: Fundación Friedrich Ebert, Marzo 2019. Disponible en: https://www.fes-argentina.org/, Victoria Basualdo, María Alejandra Esponda, Guillermo Gianibelli y Diego Morales, Tercerización y derechos laborales en la Argentina actual, Universidad Nacional de Quilmes-Página 12, 2015, y Victoria Basualdo y Diego Morales (coords.), La tercerización laboral: orígenes, impactos y claves para su análisis en América Latina, Buenos Aires, Editorial Siglo Veintiuno, 2014.

${ }_{8}^{8}$ Resulta imposible abordar en este marco en forma cabal el impacto económico de las medidas de aislamiento en las sucesivas etapas. Para la profundización de ese eje recomendamos consultar: Pablo Manzanelli, Daniela Calvo y Eduardo M. Basualdo, "Un balance preliminar de la crisis económica en la Argentina en el marco del coronavirus", CIFRA-CTA y AEyT de FLACSO, Junio de 2020 .
} 
primeras se incluyó desde el comienzo al personal de salud, de las fuerzas de seguridad, de transporte, de cuidado de personas y producción alimentaria, entre otras, y a esto siguió luego la sucesiva y progresiva habilitación de otras actividades económicas en diversas etapas y fases, con criterios de delimitación territorial. Esta situación extraordinaria tuvo efectos significativos en la organización social, en la circulación de personas y en el mundo del trabajo, en un contexto además de crecientes tensiones entre el estado, los sectores empresariales, y la clase trabajadora. Al tiempo que diversos trabajadores/as y sindicatos se preocuparon centralmente por la pérdida de puestos de trabajo y la modificación regresiva de las condiciones laborales, los sectores empresariales procuraron a toda costa mantener los niveles de rentabilidad, o en casos en que fuera imposible, morigerar la reducción. En un contexto de crisis sanitaria, económica y laboral mundial, el desplazamiento del foco de la pandemia a América Latina causa preocupación especial debida tanto a los déficits del sistema de salud pública como a las características de la estructura económica y social, con sectores considerables en condiciones de gran vulnerabilidad habitacional, de ingresos y alimentación. ${ }^{9}$

En marzo de 2020 la Organización Internacional del Trabajo (OIT) publicó el documento "El COVID-19 y el mundo del trabajo: Repercusiones y respuestas", en el que dejó claro que esta pandemia no sólo implicó efectos devastadores inmediatos en el campo sanitario, sino que a partir de las políticas de aislamiento necesarias para enfrentarla también generó crisis económicas con consecuencias serias en las condiciones de vida y de trabajo de la población. A su vez, la OIT subrayó los impactos negativos en el mundo del trabajo en al menos tres aspectos: la evolución del empleo (tanto en materia de desempleo como de subempleo); la calidad del trabajo (con respecto a los salarios y el acceso a protección social); y los efectos en los grupos específicos más vulnerables frente a las consecuencias adversas en el mercado laboral. Poco después, la OIT publicó otro documento titulado "Las normas de la OIT y el COVID-19 (coronavirus)", con una serie de recomendaciones a partir de la normativa vigente para la preservación de los puestos de trabajo y de condiciones dignas de vida, enfatizando que los gobiernos deben procurar medidas para el sostenimiento del empleo y la protección social al mismo tiempo que garantizar la estabilidad y continuidad de las empresas a través de medidas de estímulo fiscal y monetario.

En este marco de discusión deben interpretarse el conjunto de medidas tomadas por el gobierno nacional, tendientes a intervenir y regular las consecuencias del ASPO en el empleo en los ingresos, que incluyeron medidas de

\footnotetext{
9 Ver Grupo de Trabajo CLACSO "Economía popular: mapeo teórico y práctico", "Economías populares en la pandemia: cartografía provisoria en tiempos de aislamiento y crisis global", Junio 2020, y OIT-CEPAL, "La pandemia por COVID-19 podría incrementar el trabajo infantil en América Latina y el Caribe", 11 de junio de 2020.
} 
asignación de ingresos a sectores vulnerables, un amplio arco de medidas regulatorias (referidas al pago de servicios públicos, a períodos y cuotas de préstamos, precios máximos, congelamiento de tarifas), y asignación de fondos al sector productivo, ciencia y salud. ${ }^{10} \mathrm{~A}$ pesar de estas medidas, se verifica a lo largo del período un impacto muy fuerte en términos económicos, sociales y laborales y una disputa constante en torno aquién y cómo debe afrontar los costos de la crisis, siendo una iniciativa importante en este sentido la ley de "Aporte Solidario y Extraordinario de las grandes fortunas", que fue aprobada recientemente tras varios meses de dilaciones y presiones. ${ }^{11}$

Este proceso tuvo lugar en el marco de un mercado laboral sumamente heterogéneo en Argentina. Según se destaca en el informe de CIFRA-CTA de abril del 2020, del total de trabajadores/as ocupados/as poco menos de la mitad son empleados/as en relación de dependencia con contrato laboral registrado $(47,7 \%)$. De la mitad restante, el $26 \%$ son asalariados pero no registrados y el otro $26 \%$ no son asalariados, sino en su mayoría cuentapropistas. ${ }^{12}$

\footnotetext{
${ }^{10}$ Por no ser el foco central del trabajo no podremos abordar aquí la totalidad de medidas tomadas por el gobierno en el marco de la pandemia, que se pueden consultar en: https://www.argentina.gob.ar/coronavirus/medidas-gobierno, algunas de las cuales fueron objeto de tensiones y disputas como los subsidios a las empresas (reducción de contribuciones patronales, Programa de Asistencia de Emergencia al Trabajo y la Producción), y un decreto de actualización de haberes jubilatorios que, aunque garantizó aumentos, lo hizo en montos inferiores a los que estipulaba la Ley de Movilidad Jubilatoria anterior. Ver también CETyDUNSAM, "Politicas Sociolaborales en tiempos del COVID-19. Cobertura y desafíos futuros", 2 de junio de 2020. Disponible en: http://noticias.unsam.edu.ar/wp-content/uploads/2020/06/CETyDPoliticas-sociolaborales-en-tiempos-de-Covid19.pdf

11 https://www.telam.com.ar/notas/202012/537433-aporte-solidario-ley-manejo-fuego-senado.html Para más detalles sobre la ley puede verse: https://www.cronista.com/economiapolitica/Puntopor-punto-a-quien-alcanza-el-impuesto-a-las-grandes-fortunas-que-comienza-a-tratarse-hoy-enel-Senado-20201124-0010.html y también CIFRA-CTA, “Trabajo, sindicatos y Estado en la crisis generada por el COVID-19", Mayo de 2020. Disponible en: http://www.centrocifra.org.ar/docs/Trabajo\%20sindicatos\%20y\%20Estado\%20en $\% 201$ a $\% 20$ crisis. pdf

12 Datos de informe CIFRA-CTA, "Medidas socioeconómicas ante la crisis provocada por el Coronavirus", Abril 2020. Disponible en: http://www.centrocifra.org.ar/
} 
Gráfico 1. Composición de los ocupados/as según categoría ocupacional, 2019 (en \%)

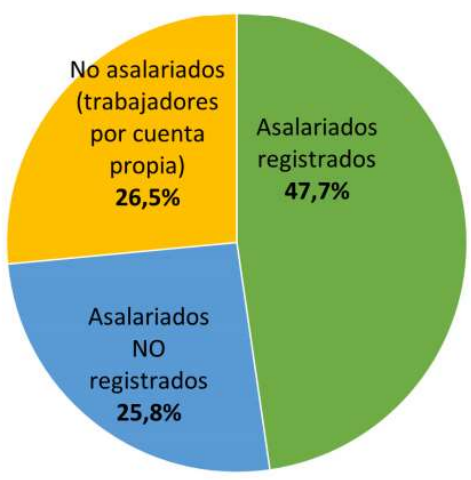

Fuente: CIFRA-CTA, Informe Abril 2020, elaborado en base a datos de INDEC.

De los trabajadores/as registrados/as (9,8 millones), un 62,3\% corresponde al sector privado (6,1 millones), un $32,6 \%$ al sector público (3,2 millones) y medio millón al régimen de casas particulares. 2.400.000 de trabajadores/as corresponden al régimen de monotributo, autónomos y monotributo social.

Gráfico 2. Trabajadores/as registrados/as según modalidad ocupacional, 2019 (en millones)

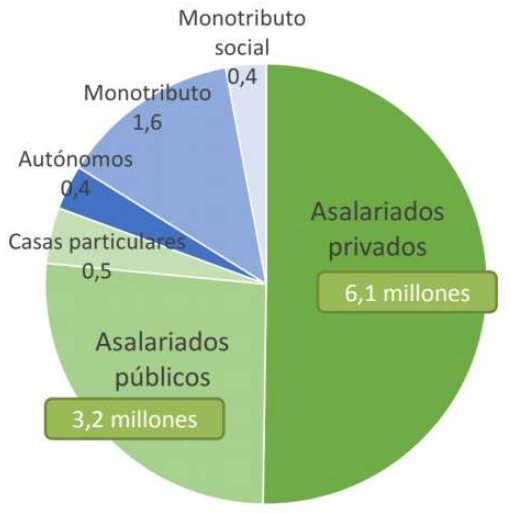

Fuente: CIFRA-CTA, Informe Abril 2020, elaborado en base a datos de INDEC.

Las medidas de aislamiento, particularmente la imposición de una cuarentena obligatoria en todo el territorio nacional desde el 20 de marzo, ocasionaron impactos en una gran cantidad de segmentos y sectores. ${ }^{13}$ En una primera

${ }^{13}$ Diversos estudios relevaron impactos significativos de la pandemia en las relaciones sociales y laborales, ver por ejemplo Comisión de Ciencias Sociales de la Unidad Coronavirus COVID-19, 
instancia, dividió a los trabajadores/as en dos colectivos, trabajadores/as esenciales y no esenciales, ocasionando problemáticas diferenciadas. Los/as trabajadores/as esenciales tuvieron que enfrentar numerosas problemáticas vinculadas con condiciones de salubridad, muy especialmente (pero no únicamente) el personal de la salud que se vio expuesto a la falta de insumos para el cuidado, al contagio y a una intensidad de trabajo mucho mayor. A esto se sumó la exposición de una gran cantidad de otros/as trabajadores/as menos visibles de ocupaciones esenciales, siendo un caso particular el de los/as trabajadores/as de plataformas dedicados a entregas a domicilio, que se vieron expuestos a un importante aumento de la demanda de trabajo y a los/as que ni siquiera se les reconoce encuadramiento en una relación laboral. ${ }^{14}$

Los/as trabajadores/as no esenciales, que en principio pudieron protegerse quedándose en sus hogares, enfrentaron otras complejas problemáticas. Los/as trabajadores/as no registrados/as perdieron su fuente laboral en su gran mayoría, por tratarse de trabajos presenciales, pudiendo quedarse en sus casas pero sin ingresos. Los/as cuentapropistas vinculados con bienes y servicios suspendidos por la pandemia se vieron fuertemente afectados y en algunos casos vieron sus ingresos interrumpidos abruptamente. Aquellos/as que pudieron sostener tareas mediante teletrabajo y seguir cobrando su salario, también vieron extendida la jornada laboral en muchos casos, la mayoría sin regulación alguna (con algunas excepciones que vale la pena subrayar, como los trabajadores/as judiciales), con una carga adicional por tener que reacondicionar las formas de trabajo a nuevos formatos, herramientas y procedimientos, y sin contar en muchos casos con la infraestructura básica ni el equipamiento para construir un espacio de oficina en el hogar. ${ }^{15}$ Esto adquirió un peso particular en el caso de los/as trabajadores/as

"Relevamiento del impacto social de las medidas del Aislamiento dispuestas por el PEN", abril de 2020 y Cora Arias, Juan Bonnin, María Bulloni, AndreaDel Bono, Ana Di Giovambattista, Ana Gárriz,Julieta Haidar, Ana Natalucci y Federico Vocos, "Trabajo en cuarentena. Encuesta realizada en el marco del proyecto Monitor Laboral COVID-19", CITRA-UMET, Julio 2020.

${ }^{14}$ Ver Christoph Ernst y Elva López Mourelo, “La COVID-19 y el mundo del trabajo en Argentina: impacto y respuestas de política", OIT, 20 de abril de 2020. Disponible en: https://www.ilo.org/wcmsp5/groups/public/---americas/---ro-lima/---ilobuenos_aires/documents/publication/wcms_740742.pdf

${ }^{15}$ La problemática del teletrabajo es particularmente relevante. Un caso significativo de regulación temprana fue el "Convenio regulador de la modalidad de teletrabajo durante la vigencia de las restricciones de la pandemia del virus COVID-19 (Coronavirus)" $\mathrm{N}^{\circ} 526 \mathrm{~T}^{\circ}$ XII, $\mathrm{F}^{\circ} 41$ firmado el 25 de abril de 2020 por la Corte Suprema de la Provincia de Buenos Aires y la Asociación Judicial Bonaerense. Recientemente se aprobó una regulación del teletrabajo en la actividad docente, aunque varios sindicatos exigen regulaciones adicionales: https://www.infobae.com/educacion/2020/06/04/el-gobierno-regulo-el-teletrabajo-de-losdocentes-y-puso-un-maximo-de-horas-de-clase/El 30 de julio de 2020 se aprobó la ley de Teletrabajo en Argentina: https://www.pagina12.com.ar/281854-se-aprobo-la-ley-de-teletrabajo en medio de fuertes debates. Para un estudio comparativo de legislación en la materia en 
vinculados al ámbito de la educación, quienes debieron reconvertir su trabajo docente a condiciones virtuales y atender una amplia gama de problemáticas excediendo con mucho lo educacional, con horarios de trabajo extendidos y numerosas deficiencias en el soporte, guía técnica, plataformas virtuales, herramientas básicas e insumos. ${ }^{16}$

El trabajo doméstico remunerado, abrumadoramente a cargo de trabajadoras mujeres, se vio también afectado gravemente, ya que la posibilidad de trabajo presencial fue suspendida por el establecimiento de la cuarentena (contexto en que existieron sectores que no continuaron pagando los salarios, ocasionando una pérdida de ingresos para los/as trabajadores/as), al tiempo que la progresiva reapertura implicó riesgos por la difícil garantía de implementos de seguridad y salud en los espacios de trabajo, y por la exposición que implican los traslados. ${ }^{17}$

Como veremos en la revisión de conflictos, los/as trabajadores/as del sector privado también se vieron afectados en algunos casos por la imposibilidad de las empresas de pagar sus sueldos, y en otros casos por la decisión de las empresas de mantener sus niveles de ganancia al costo que se requiera, lo que las llevó a promover la reapertura de actividades sin condiciones básicas de salud y protección, y exponer a los/as trabajadores/as y sus familias al contagio.

El impacto de estos cambios debe analizarse también desde una perspectiva de género, y una gran cantidad de aportes regionales e internacionales subrayan el impacto diferencial que ha tenido sobre las trabajadoras mujeres. ${ }^{18}$ En términos generales las medidas de aislamiento implicaron una sobrecarga en función de las tareas de cuidado de mayores y menores, así como de limpieza y mantenimiento de los hogares. Este cuidado de niños/as, adolescentes y mayores y el trabajo tendiente a garantizar las condiciones de reproducción social en el hogar (con las complejidades adicionales logísticas provocadas por la pandemia en términos de abastecimiento, limpieza y cuidados), lo cual, debido a las inequidades persistentes en la distribución de trabajos de cuidado y reproducción social,

América Latina ver Claudio San Juan, “Estudio comparado de la legislación sobre Teletrabajo en los países deAmérica Latina y el Caribe", Junio de 2020, disponible en: https://redsstalc.blogspot.com/2020/07/larga-vida-al-teletrabajo.html

${ }^{16}$ IDESBA-SUTEBA, "Primera presentación de resultados de la Encuesta Provincial de Trabajo Docente en contexto de Aislamiento Obligatorio", 25 de junio de 2020. Disponible en: https://www.suteba.org.ar/download/encuesta-provincial-de-trabajo-docente-en-contexto-deaislamiento-se-presentaron-los-resultados-84841.pdf

${ }_{17}$ Ver Elva López Mourelo, "La COVID-19 y el trabajo doméstico en Argentina”, OIT, 20 de abril de 2020.

18 Ver por ejemplo António Guterres, "La pandemia expone y explota desigualdades de todo tipo, incluida la de género", Naciones Unidas, 30 de abril de 2020. Disponible en: https://www.un.org/es/coronavirus/articles/guterres-covid-19-expone-desigualdad-genero, y Naciones Unidas, "TheImpact of COVID-19 onWomen", 9 de abril de 2020. 
recayó en una proporción mucho mayor en las mujeres. ${ }^{19}$ Excepto en el caso de la administración pública nacional que dio licencia a trabajadores/as a cargo de menoresy en los casos del sector privado en que esto se aplicó debidamente, en las demás ocupaciones desarrolladas en la modalidad de teletrabajoesto implicó la necesidad de desempeñar sus ocupaciones y realizar tareas de cuidado en forma simultánea. ${ }^{20}$ En el caso de los/as menores en edad escolar, la suspensión total de clases presenciales desde el 16 de marzo implicó la necesidad de garantizar el desarrollo de la escolaridad en los hogares, resaltando que sectores significativos de la población no tienen los mínimos requisitos para garantizar una convivencia adecuada de los integrantes del hogar, y mucho menos para ser al mismo tiempo lugar de trabajo y espacio de escolarización, ocio y descanso. En el caso de habitantes de villas de emergencia y barrios populares, esta situación se agravó hasta un extremo intolerable e inhumano, en casos de ausencia de servicios básicos como electricidad o agua, por condiciones de hacinamiento y precariedad extrema de las viviendas, y por la falta de alimentos y bienes fundamentales, para enfrentar lo cual también tuvieron un papel fundamental las mujeres, en muchos casos las articuladoras centrales de las redes de cuidado y organización. ${ }^{21}$ En lo que se refiere al papel importante cumplido por los comedores escolares en la educación pública para proveer alimentación a un sector vulnerable, se implementó la entrega de bolsones de comida cuyo carácter, alcance y forma de distribución se fue mejorando al calor de disputas y exigencias con fuerte apoyo de los gremios docentes.

Tanto la pandemia en sí como la crisis económica y laboral y el proceso acelerado de cambio de condiciones a nivel mundial y nacional, en combinación con la reclusión en el espacio privado de los hogares para una gran mayoría de la población en el comienzo del período y para un porcentaje significativo aún a

19 Ver Pronunciamiento colectivo de Asamblea de Trabajadoras en tiempos de pandemia, disponible en: http://www.hamartia.com.ar/2020/07/02/asamblea-de-trabajadoras/

20: Más allá de lo que debería suceder (http://redisindical.org/wp-content/uploads/2020/04/cta__comunicado_de_asesoria_juridica_por_licencia_coronavirus.pdf), notas periodísticas y relevamientos informales parecen señalar que existen fuertes limitaciones y resistencias a su aplicación en el sector privado, ver por ejemplo: https://www.perfil.com/noticias/economia/incentivo-fiscal-para-empresas-que-impulsenigualdad-y-licencia.phtml.

${ }^{21}$ Esto asumió una especial gravedad en el distrito de CABA, donde el Jefe de Gobierno Horacio Rodríguez Larreta, que incluso llegó a apelar cuando lo intimaron a proveer agua potable a las villas (https://www.pagina12.com.ar/269148-coronavirus-la-justicia-intima-al-gobierno-portenoa-proveer). Esta política generó diversas acciones judiciales contra el gobierno de la CABA, recientemente se logró por vía judicial dar lugar a reclamos referidos a la falta de provisión de elementos básicos de protección indispensables para los trabajadores/as de la salud: https://www.cta.org.ar/nuevo-reves-de-la-justicia-para-el.html 
finales de la etapa estudiada, implicó además diversos efectos en la salud mental de sectores de la población. Esto generó impactos psicosociales que se fueron modificando y profundizando a lo largo del proceso y con distintas particularidades en las diversas franjas etarias de la población. Además, la situación de aislamiento puso presión adicional sobre un fenómeno muy serio ya existente de violencia de género y violencia familiar, así como situaciones de maltrato infantil y abusos, cuya evolución genera un enorme problema de política pública. En un contexto que genera presión adicional y volvió más difícil la visibilización y denuncia, esto fue afrontado con medidas y mecanismos de protección por parte de un amplio arco de organizaciones y del Ministerio de Mujeres, Géneros y Diversidad de la Nación. A pesar de ello, informes recientes indican que se cometieron 57 femicidios desde la implementación del ASPO hasta el 28 de mayo, siendo éste un indicador extremo de una problemática de violencia de género mucho más extendida. ${ }^{22} \mathrm{Al}$ mismo tiempo, la aplicación de políticas de aislamiento obligatorio otorgó un papel significativo a las fuerzas de seguridad, que en distintas ocasiones protagonizaron procesos represivos ilegales contra distintos sectores de la población, siendo la violencia institucional una cuestión muy relevante en la agenda política del período. ${ }^{23}$

Se trata entonces de un período de una complejidad extrema, no sólo por el desarrollo de la pandemia sino porque las medidas indispensables para combatirla agudizan y vuelven más extremos una serie de fenómenos estructurales vinculados con la pobreza ${ }^{24}$, el déficit habitacional y de infraestructura, las desigualdades en el mercado de trabajo y la precariedad laboral, y la violencia de género y familiar, por mencionar sólo algunas, al tiempo que los déficits de salud y educación pública se convierten en problemas acuciantes. A esto se suma que se trata de un proceso dinámico y cambiante, con

\footnotetext{
22 "Informe sobre femicidios en Argentina" que abarca el período del 20 de marzo al 28 de mayo elaborado por el Observatorio de Femicidios en Argentina "Adriana Marisel Zambrano", que depende de La Casa del Encuentro. Consultar también el informe de la Oficina de Violencia de Género de la Suprema Corte de Justicia de la Nación, "Informe sobre las presentaciones en OVD durante el período de aislamiento social, preventivo y obligatorio", Julio 2020.

${ }^{23}$ Existieron diversas denuncias de violencia institucional en diversos puntos del territorio nacional, siendo los casos de Luis Espinoza, un trabajador rural brutalmente asesinado por policías en Tucumán el 15 de mayo de 2020, y el de la represión violenta a una comunidad qom en Chaco a comienzos de junio de 2020 dos casos extremos. A estos se sumó el caso de Facundo Astudillo Castro, que continúa desaparecido desde el 30 de abril tras haber sido visto por última vez en el sur de la Provincia de Buenos Aires, y que cuenta con diversos indicios que apuntan a la responsabilidad de la Policía Bonaerense.

${ }^{24} \mathrm{El}$ índice de pobreza durante el primer semestre se elevó a 40,9\% de la población del país y el de indigencia al 10,5\%, según medición del INDEC. Ver: https://www.indec.gob.ar/uploads/informesdeprensa/eph_pobreza_01_200703093514.pdf
} 
alteraciones significativas en períodos cortos, lo que implica tener que periodizar cuidadosamente tanto en función de medidas como de dinámicas resultantes.

\section{LA CONFLICTIVIDAD LABORAL EN EL CONTEXTO DE AISLAMIENTO OBLIGATORIO POR LA PANDEMIA COVID-19}

En este contexto, este artículo se propone contribuir a visibilizar un aspecto poco abordado: las formas de protesta y conflicto laboral y sindical, tanto en un contexto de paralización de una parte significativa de la economía como el que implica el aislamiento obligatorio, como en los procesos de reapertura parcial que fueron desplegándose en cada una de las etapas hasta fines de mayo de 2020, los cuales se dieron en vinculación con una serie de líneas de acción y estrategias desarrolladas por sectores empresariales. En un contexto de escasos relevamientos abarcativos y globales de las relaciones laborales, aún menos aproximaciones hicieron foco específico en las situaciones de conflictividad laboral y/o gremial desatadas tras la declaración del ASPO y las estrategias de lucha desplegadas por la clase trabajadora en el marco de la pandemia.Una razón para que esto ocurra es el enorme desafío conceptual, metodológico y de fuentes que implica intentar una aproximación a este período, para el que no disponemos de fuentes oficiales aún. ${ }^{25} \mathrm{Al}$ mismo tiempo, en el contexto de los cambios profundos en la dinámica laboral y sindical como resultado del aislamiento, la conceptualización de "conflictividad" se encuentra en construcción y definición. Aquí partiremos de una definición sencilla y amplia de "conflicto laboral", entendido como disputa de derecho o de interés entre empleadores y empleados/as, que puede llevarse adelante tanto por grupos de trabajadores/as como por representantes y/o organizaciones sindicales en interpelación a los empresarios/empleadores o sus representantes.

Esta aproximación se basa en un proceso de rastreo y trabajo sobre un conjunto de fuentes que incluyen: informes de centros vinculados a organizaciones sindicales, otros informes de organizaciones como el Centro de Economía Política Argentina (CEPA), aportes desde equipos académicos como los del Equipo de Estudio sobre sindicalismo, conflicto y territorio (CEIL-CONICET),

\footnotetext{
${ }^{25}$ Resulta particularmente valiosa la base de datos del Ministerio de Trabajo de la Nación, que registra la información mensual de los conflictos laborales que tuvieron lugar en el territorio nacional a partir de la consulta diaria de más de 120 medios electrónicos disponibles en internet (ver: http://trabajo.gob.ar/estadisticas/conflictoslaborales/index.asp). En ese marco se realizan informes trimestrales, semestrales y anuales con datos agregados considerando para su análisis las siguiente variables de clasificación: ámbito institucional del empleador, actividad económica, nivel de agregación, localización geográfica, orientación del reclamo, actor sindical, autoridad de intervención, tipo de conflicto, tipo de acción y duración de la acción. No hay sin embargo informes accesibles ni publicados de este equipo para este período, seguramente debido a la cercanía temporal y también al corte que implica la pandemia y las medidas de aislamiento en las dinámicas tradicionalmente analizadas de conflicto laboral.
} 
noticias e informes de portales y medios digitales con secciones laborales y sindicales, y reportes de colectivos como "Basta de Asesinatos Laborales" ${ }^{26}$ En particular, los informes elaborados por el Observatorio del Derecho Social (ODS) de la CTA Autónoma poseen una síntesis valiosa de los principales ejes de conflictividad laboral durante el período, a partir de un seguimiento que vienen realizando a largo plazo de procesos de conflicto laboral, mayoritariamente centrados en sectores registrados y sindicalizados, pero con una amplia cobertura. En diversos portales de noticias como ANRed, Infogremiales, LetraP, La Izquierda Diario, Mundo Gremial, El Destape, La Nación Trabajadora y Enfoque Sindical, así como en columnas sindicales en algunos medios (se destaca en particular la del dirigente sindical Victorio Paulón en el sitio "El cohete a la luna"), además de sitios de las propias organizaciones y/o federaciones y confederaciones sindicales, rastreamos una gran diversidad de conflictos laborales y gremiales que no se encuentran sistematizados. También recurrimos a informes y noticias en diferentes periódicos de tirada nacional, así como a documentos sindicales escritos, denuncias, material audiovisual publicado en las redes por agrupaciones sindicales, sindicatos, sectores de trabajadores y agrupamientos diversos, e información provista por contactos sindicales y por trabajadores/as. No se pretende aquí lograr un panorama exhaustivo, sino un análisis de casos y procesos relevantes para caracterizar cada etapa. Aún cuando no se aplicó un recorte territorial, las fuentes utilizadas reflejan en su mayoría conflictos de trabajadores/as registrados/as y con algún tipo de organización sindical con una representación mayoritaria de la zona del Área Metropolitana de Buenos Aires (AMBA) y de los grandes aglomerados urbanos del país, siendo muy limitado el abordaje de las problemáticas de trabajadores/as no registrados y de otros territorios y regiones.

Se desarrollará a continuación un análisis por etapas que permitirá abordar algunos de los ejes centrales de la conflictividad laboral del período, recuperando algunos de los procesos más destacados y reconstruyendo al mismo tiempo algunas de las políticas empresariales más destacadas en cada etapa. Entre los núcleos centrales pueden señalarse:

\footnotetext{
26 Sitios para descargar informes:http://ods.ctaautonoma.org.ar/, https://www.facebook.com/bastadeasesinatoslaborales/El espacio "Basta de Asesinatos Laborales" (BAL) surge como un espacio de trabajo sobre las muertes en los lugares de trabajo, del que participanactivistas sindicales, investigadores y especialistas del Taller de Estudios Laborales. En diciembre de 2018 presentaron su primer informe anual, y en el marco de la pandemia están realizando una encuesta para trabajadores/as y sindicalistas a partir de la cual realizan informes periódicos sobre los impactos de la crisis del COVID-19 diversas actividades económicas. Para más información, ver: https://www.anred.org/2019/05/17/basta-de-asesinatoslaborales/
} 


\section{Cuadro 1. Ejes centrales de la conflictividad laboral por período de la ASPO}

\section{Períodos del \\ Ejes centrales de conflicto laboral}

ASPO

\begin{tabular}{|c|c|}
\hline $\begin{array}{l}\text { Primer período: } \\
20 \text { de marzo - } \\
2 \text { de abril }\end{array}$ & $\begin{array}{l}\text { Diversos colectivos de trabajadores/as exigieron el cumplimiento } \\
\text { del aislamiento dictado y que sólo se habilitaran bienes y servicios } \\
\text { esenciales para la sociedad y aquellas actividades sanitarias } \\
\text { orientadas a combatir la pandemia, ante intentos empresariales } \\
\text { para lograr la excepción para todo tipo de actividades. Otros } \\
\text { colectivos de trabajadores/as que debieron continuar con sus } \\
\text { labores durante el ASPO se orientaron a la exigencia de medidas de } \\
\text { protección y salubridad efectivas y/o de reconversión de sectores y } \\
\text { procesos de trabajo. Se dieron las primeras denuncias contra } \\
\text { empresas que utilizaron mecanismos para descargar sus costos } \\
\text { sobre los/as trabajadores/as como despidos, suspensiones, recortes } \\
\text { salariales, negativa a otorgar las licencias pagas correspondientes, } \\
\text { etc. El } 28 / 3 \text { se produjo el despido de } 1450 \text { trabajadores/as de la } \\
\text { construcción por parte del grupo económico Techint, seguido de } \\
\text { una fuerte respuesta oficial que culmina en el Decreto de } \\
\text { prohibición de despidos del } 31 / 3 / 2020 \text {. }\end{array}$ \\
\hline $\begin{array}{l}\text { Segundo y tercer } \\
\text { período: } 3 \text { de } \\
\text { abril - } \\
26 \text { de abril }\end{array}$ & $\begin{array}{l}\text { Durante este período se profundizaron y tomaron la delantera las } \\
\text { tentativas empresariales para transferir los costos de la crisis a } \\
\text { los/as trabajadores/as. Diversas fuentes registraron desde mediados } \\
\text { de abril un salto cualitativo en la cantidad de trabajadores/as } \\
\text { afectados por despidos, suspensiones y rebajas salariales, y la } \\
\text { conflictividad laboral comenzó a orientarse a frenar estas } \\
\text { tendencias. En este período comenzó a tener una mayor relevancia } \\
\text { la participación de sindicatos nacionales por rama, algunos de los } \\
\text { cuales acordaron a través de negociación colectiva con cámaras } \\
\text { empresariales suspensiones y recortes salariales que, sin embargo, } \\
\text { fueron discutidas en muchos casos por seccionales y } \\
\text { organizaciones de trabajadores/as de base. }\end{array}$ \\
\hline
\end{tabular}




\begin{tabular}{|c|c|}
\hline $\begin{array}{l}\text { Cuarto período: } \\
27 \text { de abril - } 10 \\
\text { de mayo }\end{array}$ & $\begin{array}{l}\text { El } 28 \text { de abril se firmó un acuerdo entre la Unión Industrial } \\
\text { Argentina (UIA) y la Confederación General del Trabajo (CGT), } \\
\text { homologado por el Ministerio de Trabajo, que institucionalizó y } \\
\text { legalizó la estrategia empresarial que se venía desarrollando } \\
\text { previamente. Las suspensiones y los recortes salariales se } \\
\text { generalizaron en varios sectores, en algunos casos a través de } \\
\text { instancias de negociación colectiva por sector con homologación de } \\
\text { la cartera laboral, y en otros por avance de facto de las direcciones } \\
\text { empresariales; aunque la conflictividad a nivel de seccionales y } \\
\text { lugares de trabajo continuó desarrollándose. Se lograron también } \\
\text { negociaciones paritarias que se dirigieron en otro sentido, } \\
\text { plasmando demandas de los trabajadores/as. }\end{array}$ \\
\hline $\begin{array}{l}\text { Quinto período: } \\
11 \text { de mayo - } \\
25 \text { de mayo }\end{array}$ & $\begin{array}{l}\text { El } 18 \text { de mayo el Decreto 487/2020 prorrogó la "prohibición de } \\
\text { despidos y suspensiones" por } 60 \text { días, pero éstos continuaron, junto } \\
\text { con los recortes salariales. Otras estrategias empresariales fueron el } \\
\text { lockout (el caso de la empresa siderúrgica Siderca del grupo } \\
\text { Techint en Campana) y las amenazas de traslado de producción a } \\
\text { plantas de otros países (el caso de Acindar Villa Constitución que } \\
\text { amenazó con trasladar parte de su producción a Brasil), en clara } \\
\text { actitud de amedrentamiento para los/as trabajadores/as y sus } \\
\text { organizaciones gremiales. Otras grandes empresas involucradas en } \\
\text { despidos y suspensiones durante el ASPO, lograron recibir el } \\
\text { subsidio estatal de la Asignación de Emergencia para el Trabajo y } \\
\text { la Producción(ATP), mientras que empresas recuperadas por sus } \\
\text { trabajadores/as y cooperativas de trabajo quedaron sin acceso y con } \\
\text { enormes dificultades para continuar en actividad. Hacia el final del } \\
\text { período, se produjo la reanudación progresiva de muchos sectores } \\
\text { de la producción industrial que hasta allí no habían retornado a su } \\
\text { trabajo, lo que abrió disputas por los contenidos y las formas en } \\
\text { relación a los protocolos de higiene y seguridad a aplicar, y } \\
\text { acciones ante posibles contagios en las plantas. }\end{array}$ \\
\hline
\end{tabular}

\section{Primer período: 20 de marzo-2 de abril}

En términos de las políticas públicas, cabe recordar que a partir del 10 de marzo, mediante las resoluciones 178 y 184, el gobierno otorgó licencias con percepción íntegra de salarios para la población que pueda haber tomado contacto con el virus o sea portadora, asignando además tareas en forma remota para el sector público. Desde el 16 de marzo se suspendió la asistencia al lugar de trabajo para población de riesgo y licencias para el sector educativo, una vez suspendidas las clases, al tiempo que se recomendaron tareas remotas para los sectores que pudieran hacerlo. El 20 de marzo se promulgó el decreto 297 que define el ASPO general. El 24 de marzo el gobierno implantó el Ingreso Familiar 
de Emergencia (IFE) a través del decreto 310. El 31 de marzo se decretó la "prohibición de despidos y suspensiones" (decreto 329), con la excepción de las suspensiones efectuadas en los términos del artículo 223 bis de la Ley de Contrato de Trabajo. ${ }^{27}$ Diversas empresas utilizaron la excepción para avanzar con suspensiones con reducción salarial, contando con la homologación del Ministerio de Trabajo, comenzando por el grupo Techint. Desde el 1 de abril se estableció el Programa de Asistencia de Emergencia al Trabajo y la Producción (decreto 332, luego ampliado por el decreto 376), cuyo montoes equivalenteal 50\% del salario neto del trabajador, con un mínimo de un SMVM y un máximo de dos SMVM. Se amplió a empresas de más de 800 trabajadores/as, lo que resultó en que puedan beneficiarse grandes empresas transnacionales como Acindar, Volkswagen y Latam. En términos de la evolución de la pandemia en el período, al final del mismo, el 2 de abril, las víctimas fatales totales sumaban 36 y el total de personas contagiadas en todo el país desde el inicio de la pandemia era de 1.265. ${ }^{28}$

La mayoría de conflictos laborales durante este período inicial del ASPO se dieron encabezados por trabajadores/as de base, cuerpos de delegados/as, comisiones internas $\mathrm{y}$, en algunos casos puntuales, por sindicatos seccionales y nacionales. Tuvieron como eje el cuidado de las condiciones de salud y seguridad para los/as trabajadores/as y una serie de disputas más de fondo, en torno a qué producciones y servicios debían considerarse "esenciales" en el marco de la pandemia, y alrededor de la reconversión de sectores, tareas y procesos de trabajo. En muchos casos, los/as trabajadores/as y sus organizaciones de base actuaron de hecho para garantizar condiciones de trabajo más seguras y saludables.

Según el informe elaborado por el ODS de la CTA Autónoma el 30 de marzo ${ }^{29}$, basado en una sistematización de más de 70 denuncias y reclamos colectivos de trabajadores/as de diferentes actividades del país, los/as trabajadores/as que debieron seguir concurriendo a sus espacios laborales durante esta etapa ${ }^{30}$ se

\footnotetext{
${ }^{27}$ El art. 223 bis de la LCT sostiene que: "Se considerará prestación no remunerativa las asignaciones en dinero que se entreguen en compensación por suspensiones de la prestación laboral y que se fundaren en las causales de falta o disminución de trabajo, no imputables al empleador, o fuerza mayor debidamente comprobada, pactadas individual o colectivamente y homologadas por la autoridad de aplicación, conforme normas legales vigentes, y cuando en virtud de tales causales el trabajador no realice la prestación laboral a su cargo. Sólo tributará las contribuciones establecidas en las Leyes Nros. 23.660 y 23.661." (Artículo incorporado por art. 3 de la Ley $\mathrm{N}^{\circ} 24.700$ B.O. 14/10/1996)

${ }^{28} \mathrm{https}$ ///argentina.as.com/argentina/2020/04/02/tikitakas/1585817215_723362.html

${ }^{29}$ Observatorio del Derecho Social de la CTA Autónoma, "El trabajo en el marco de la emergencia sanitaria. Propuestas urgentes para la cuarentena", 30 de marzo de 2020. Disponible en: http://ods.ctaautonoma.org.ar/2020/03/30/el-trabajo-en-el-marco-de-la-emergencia-sanitaria/

${ }^{30}$ El DNU original enumeraba 24 sectores de producción y servicios cuyo personal estaba exceptuado de cumplir con el aislamiento. Durante días siguientes se fueron agregando otros sectores a través de sucesivas normas.
} 
enfrentaron a dos tipos de problemas. Por un lado, diversos colectivos de trabajadores/as se orientaron a la necesidad de cumplir con el aislamiento dictado y/o a que sus esfuerzos productivos se dirijan efectivamente a garantizar bienes y servicios "esenciales" para la sociedad y para aquellas actividades sanitarias orientadas a combatir la pandemia. Soul y Ciolli ${ }^{31}$ advirtieron que en el transcurso de la medida de aislamiento hasta principios de abril, surgieron criterios propios de los/as trabajadores/as contra los criterios de esencialidad adoptados por los empresarios, lo cual dio lugar a diferentes conflictos al interior de los espacios de trabajo. Por ejemplo, trabajadores/as de distintas plantas de producción de alimentos como Felfort ${ }^{32}$, Mondelez ${ }^{33}$, Bimbo (San Fernando) ${ }^{34}$, Pepsico ${ }^{35}$, Fernet Branca (Córdoba) y Quilmes (Zárate) ${ }^{36}$ cuestionaron que las golosinas, snacks, facturas congeladas y bebidas alcohólicas sean "esenciales" para la vida social, reclamaron el acatamiento de la cuarentena por parte de las empresas, y en los tres primeros casos plantearon que la producción debía reconvertirse hacia bienes efectivamente prioritarios.

Los/as trabajadores/as del Astillero Río Santiago (de propiedad estatal) realizaron asambleas y se movilizaron a la dirección de la empresa exigiendo condiciones de higiene y que se cumpla con los/as trabajadores/as que debían ser licenciados, logrando que se reduzca la jornada laboral a 5 horas por turno y que los jueves y viernes haya asueto para desinfección y acondicionamiento del espacio. Además, exigieron al Ministerio de Salud de la Provincia de Buenos Aires que destine fondos e insumos necesarios para comenzar a producir alcohol en gel en el laboratorio de ensayos, para hacer frente a la escasez de ese producto esencial. Plantearon también que el Astillero se encuentra en condiciones de fabricar módulos de atención sanitaria primarios como camas de hospitales, exigiendo a las autoridades la decisión política y los fondos para poder llevar esa producción esencial adelante. ${ }^{37}$ Finalmente, tras un acuerdo de la empresa con PAMI, comenzaron a reparar camas ortopédicas abandonadas y semi-destruidas,

\footnotetext{
31 https://www.anred.org/2020/04/04/la-esencialidad-de-la-produccion-en-una-pandemia-saludcolectiva-o-ganancia-individual/

32 http://www.laizquierdadiario.com/En-plena-cuarentena-por-la-pandemia-del-coronavirusFelfort-produce-golosinas

$33 \mathrm{ttp}$ ://infogremiales.com.ar/noticia.php?n=61604; http://infogremiales.com.ar/noticia.php?n=61584

${ }^{34}$ En el caso de Bimbo, el reclamo fue acompañado por un paro decidido en asamblea, con el acompañamiento de la comisión interna. http://www.laizquierdadiario.com/Trabajadores-deBimbo-paran-por-tiempo-indeterminado-hasta-que-la-patronal-respete-la-cuarentena

35 Placas BAL. Disponible en https://www.facebook.com/bastadeasesinatoslaborales

$36 \mathrm{http} / / \mathrm{www}$.enlacecritico.com/destacados/video-protesta-de-trabajadores-de-la-planta-dequilmes-en-zarate-nos-obligan-a-no-cumplir-la-cuarentena-obligatoria-y-no-fabricamosalimentos-de-primera-necesidad

${ }^{37}$ Placas BAL. Disponible en https://www.facebook.com/bastadeasesinatoslaborales
} 
para su utilización en hospitales de campaña. ${ }^{38}$ En el mismo sentido, empresas bajo gestión de sus trabajadores/as (que abarcan unos 400 establecimientos y aproximadamente 14.000 trabajadores/as en todo el país), aún atravesando una situación económica crítica, al borde de la supervivencia y con casi inexistentes líneas de ayuda estatal, comenzaron a reconvertir sus actividades para producir bienes y servicios que hacen a las necesidades populares y del sistema de salud en este momento crítico: espacios para aislamiento de personas en tránsito, producción de alcohol en gel, barbijos y camisolas, mascarillas, desinfectantes y muebles para hospitales, etc. ${ }^{39}$

En Córdoba, el sindicato del neumático (SUTNA) reclamó para que el Ministerio de Trabajo interceda en pos de garantizar la cuarentena en una empresa de neumáticos, lo que finalmente logró. ${ }^{40} \mathrm{El}$ reclamo se replicó en FATE (San Fernando) donde los trabajadores exigieron la suspensión total de actividades, teniendo en cuenta que la producción de neumáticos no es esencial. ${ }^{41}$ Otros sectores esgrimieron el carácter inmediato del consumo del producto como criterio para establecer la "esencialidad" de la actividad. La Unión Obrera Metalúrgica (UOM) de Campana entendió que la producción de la planta Siderca, del holding Tenaris del grupo Techint, no era esencial, puesto que se orienta a tubos de acero utilizados en excavaciones y perforaciones petrolíferas futuras. En un comunicado del 30 de marzo afirmaron que "ninguna actividad vinculada a la industria siderúrgica, metalmecánica, autopartista, ni metalúrgica de nuestra región se encuentra alcanzada por las excepciones establecidas en la normativa vigente". La empresa, con el aval de los intendentes de Campana y Zárate, sostuvo que se debía producir normalmente ya que entraba en las excepciones contempladas para el rubro de la producción y transporte de energía y debido a "necesidades impostergables en el país y compromisos de exportación", e instó de diversas maneras a que los/as trabajadores/as de la planta concurran a su lugar de trabajo (con armado de grupos de Whatsapp por jefes y gerentes, presiones a través de videos "motivacionales", solicitadas en los diarios locales, etc.). Hasta mediados de abril los/as trabajadores/as y sus representaciones sindicales sostuvieron un paro de hecho, sosteniendo

\footnotetext{
38 https://www.pagina12.com.ar/260471-coronavirus-en-astillero-rio-santiago-se-reparan-camaspara-

39 https://www.pagina12.com.ar/256193-empresas-recuperadas-contra-el-coronavirus; https://www.anred.org/2020/04/30/gestion-obrera-en-tiempos-de-pandemia/; https://www.pagina12.com.ar/254655-empresas-recuperadas-en-apuros-nuestras-cooperativasvan-a-i

40 https://www.anred.org/2020/04/04/la-esencialidad-de-la-produccion-en-una-pandemia-saludcolectiva-o-ganancia-individual/

${ }^{41}$ Placas BAL. Disponible en https://www.facebook.com/bastadeasesinatoslaborales
} 
únicamente las llamadas "áreas ininterrumpibles" (aquellas que no pueden detenerse sin causar deterioros importantes sobre los equipos de producción). ${ }^{42}$

Otros colectivos de trabajadores/as que debieron continuar con sus labores durante el ASPO se orientaron al pedido de medidas de salubridad efectivas. Según el informe realizado por el espacio "Basta de Asesinatos Laborales" al 31 de marzo, basado en encuestas a trabajadores/as de distintas ramas de producción y servicios, la mitad de los encuestados consideraba que su trabajo no debía ser considerado esencial, más de la mitad se desempeñaba en espacios no ventilados, sólo la mitad contaba con elementos de desinfección personales en su lugar de trabajo, y en la mayor parte de los casos, se afirmaba que los lugares de trabajo no establecieron protocolos para evitar aglomeraciones o para garantizar el distanciamiento de $1,5 \mathrm{mts} .{ }^{43}$

En este punto, los reclamos fueron variados. En algunos casos se reclamó insumos básicos como jabón o alcohol en gel, y que se tomaran instrucciones sobre distanciamiento social. En el sector de comercio existieron reclamos en distintas cadenas para acortar el tiempo de exposición al público, exigir la provisión de elementos de seguridad e higiene, y en algunos casos, la suspensión de actividades. ${ }^{44}{ }^{45}$ En alimentación, en la planta Pacheco de Mondelez, los/as trabajadores/as junto a la comisión interna realizaron un paro de varias horas de duración, con lo que lograron que la empresa reconozca licencias pagas para trabajadoras con hijos/as en edad escolar, y medidas y protocolos de higiene y seguridad en la planta. ${ }^{46}$ Reclamos similares, en relación a medidas para preservar la salud de los/as trabajadores/as en espacios laborales, se dieron en empresas de fabricación de papel (Celulosa Argentina y Papelera Paysandú), jabón (Procter y Gamble) y telecomunicaciones (Telecom). ${ }^{47}$ El cuerpo de delegados del Frigorífico Rioplatense reclamó a la empresa que se organice la producción para poder garantizar las medidas de prevención, disminuyendo la cantidad de personal en la planta, realizando controles regulares de temperatura y abarcando con las medidas de cuidado a los/as trabajadores/as tercerizados/as y contratados/as. En el transporte de pasajeros se dieron situaciones similares. En la línea 60 de

https://www.codigoplural.com.ar/post/malestar-en-la-ciudad-porque-tenaris-nosuspendi\%C3\%B3-sus-actividades-y-forz\%C3\%B3-a-sus-empleados-a-trabajar;

https://www.letrap.com.ar/nota/2020-3-26-10-25-0-grupo-techint-cuarentena-con-excepciones-ydenuncias-de-recortes-salariales/

${ }^{43}$ Placas BAL. Disponible en https://www.facebook.com/bastadeasesinatoslaborales

44 https://www.anred.org/2020/03/25/ni-chetos-ni-irresponsables-trabajadores-trabajadoras-ycuarentena-obligatoria/

${ }^{45}$ Placas BAL. Disponible en https://www.facebook.com/bastadeasesinatoslaborales

${ }^{46}$ https://pcr.org.ar/nota/un-triunfo-en-mondelez-pacheco

47 "El trabajo en el marco de la emergencia sanitaria. Propuestas urgentes para la cuarentena".

Observatorio del Derecho Social, CTAA. Disponible en: http://www.obderechosocial.org.ar/docs/trabajo_en_emergencia_sanitaria.pdf 
transporte colectivo de CABA, los/as trabajadores/as reunidos en asamblea impusieron la provisión de alcohol en gel en las cabeceras y la limpieza de los colectivos luego de cada recorrido. Los/as delegados/as también evacuaron alrededor de 90 trabajadores de grupos de riesgo y bloquearon los asientos delanteros reduciendo así el riesgo de contagio; también exigieron el bloqueo de la puerta delantera y que se coloque acrílicos para el habitáculo del chofer, así como el control de temperatura a los choferes al inicio y finalización de la jornada. ${ }^{48}$ En la línea Sarmiento del ferrocarril, los/as trabajadores/as lograron reducir el personal al mínimo, que no trabajen boleteros, evasión y atención al cliente. El cuerpo de delegados/as llamó a que los banderilleros dejen de concurrir (las barreras están automatizadas) y reclamó que se distribuya lavandina, alcohol, guantes y otros elementos de protección a todos los sectores, y alcohol en gel para los pasajeros/as. ${ }^{49}$

En el sector de salud, los/as trabajadores/as y algunas organizaciones sindicales como CICOP han reclamado desde la declaración del ASPO y en distintos establecimientos por condiciones de trabajo, en especial por la falta de personal y de elementos de prevención, así como por la calidad de las instalaciones hospitalarias y la precarización laboral que existe en el sector, por una partida presupuestaria de emergencia para Salud y un aumento salarial de emergencia. ${ }^{51} \mathrm{En}$ algunos casos fueron los propios trabajadores/as quienes reordenaron las instalaciones para garantizar sectores de aislamiento. ${ }^{52}$

En otros casos, los/as trabajadores/as reclamaron la conformación de comisiones mixtas de higiene y seguridad para poder establecer pautas sobre cómo producir en este contexto, teniendo en cuenta las obligaciones y recomendaciones en términos de salubridad. La Federación de Trabajadores del Complejo Industrial Oleaginoso, Desmotadores de Algodón y Afines de la República Argentinadiscutió con las cámaras empresarias la "esencialidad" de una parte importante del sector ligado a la exportación, pero no así el ligado a la alimentación. La organización sindical exigió el establecimiento de protocolos sanitarios, el cumplimiento de una serie de pautas de prevención (dotaciones mínimas, controles de temperatura, garantía de elementos sanitarios) y el control de su cumplimento a través de Comités Mixtos de Higiene y Seguridad. ${ }^{53}$

El informe del Observatorio de Derecho Social también registró, a una semana de decretado el ASPO, las primeras denuncias contra empresas que utilizaron

\footnotetext{
${ }^{48}$ Placas BAL. Disponible en https://www.facebook.com/bastadeasesinatoslaborales

${ }^{49}$ Placas BAL. Disponible en https://www.facebook.com/bastadeasesinatoslaborales

${ }^{50}$ https://www.anred.org/2020/03/23/no-son-heroes-son-trabajadores-precarizados/

${ }^{51}$ Placas BAL. Disponible en https://www.facebook.com/bastadeasesinatoslaborales

${ }^{52}$ Centro de Salud y Acción Comunitaria (CESAC) del Hospital Penna. Placas BAL, disponibles en https://www.facebook.com/bastadeasesinatoslaborales

53 http://federacionaceitera.com.ar/2020/03/21/por-la-salud-y-la-integridad-de-las-trabajadoras-ytrabajadores
} 
mecanismos para descargar los costos de la crisis sobre los/as trabajadores/as (despidos, suspensiones, recortes salariales, negativa a otorgar las licencias pagas correspondientes, etc.). En la planta SIAT Valentín Alsina, perteneciente al holding Tenaris del grupo Techint, desde el 19 de marzo la comisión interna del sindicato, en representación de los más de 250 trabajadores/as de la planta, denunció públicamente que la empresa aplicaba suspensiones masivas amparándose en un acta firmada a fines del año pasado, abonando el $85 \%$ del salario neto en carácter no remunerativo a los/as trabajadores/as y eliminando premios por producción, que representaban aproximadamente el $40 \%$ del sueldo de los empleados/as. Los/as trabajadores/as exigieron que la empresa acate la cuarentena, ya que no se encontraba dentro de las excepciones al decreto de la ASPO, y abonase los salarios al 100\%. ${ }^{54}$ Por su parte, desde el 22/03 la aerolínea Latam había tomado la decisión de recortar el 50\% de los salarios de sus 43 mil empleados/as a partir de abril y por, al menos, un trimestre ${ }^{55}$, frente a lo que los sindicatos aeronáuticos en su conjunto elaboraron un comunicado repudiando el planteo, aclarando que según las leyes nacionales la medida sería ilegal, y exigiendo el cobro íntegro de sus salarios. ${ }^{56}$ Marcando un claro punto de inflexión para la etapa, el grupo Techint, en su rama de construcciones, resolvió el 28 de marzo despedir a 1450 trabajadores que venían desempeñándose en obras contratadas con el sector privado en las provincias de Buenos Aires, Neuquén y Tucumán, adquiriendo el conflicto dimensiones públicas. ${ }^{57}$

Estos primeros conflictos en relación a despidos y suspensiones con recortes salariales se dieron aún esporádicamente y principalmente en grandes empresas de núcleos centrales de la economía. Resultan fundamentales porque marcan el camino de la estrategia que adoptará el gran empresariado local a partir de allí y de las líneas de conflictividad laboral en el futuro inmediato. Frente a este proceso, el 31 de marzo el Poder Ejecutivo decretópor medio del Decreto de Necesidad y Urgencia 329 la "prohibición de despidos y suspensiones", con la excepción de las suspensiones efectuadas en los términos del artículo 223 bis de la Ley de Contrato de Trabajo (LCT).

\section{Segunda y tercera etapa: 3 de abril-26 de abril}

Durante este período se intensificaron las iniciativas empresariales para intentar descargar la crisis sobre los/as trabajadores/as, ya expresadas claramente a fines de la etapa anterior. Si antes del DNU las suspensiones y despidos venían siendo decididos unilateralmente por las empresas, a partir de allí muchas de

54 https://www.letrap.com.ar/nota/2020-3-26-10-25-0-grupo-techint-cuarentena-con-excepciones-ydenuncias-de-recortes-salariales;https://ar.radiocut.fm/audiocut/actualidad-gremial-tenaris-siatentrevista-a-jose-villa-comision-interna/

${ }^{55} \mathrm{http}: / / \mathrm{www}$.infogremiales.com.ar/noticia.php?n=61580

${ }^{56} \mathrm{http}: / / \mathrm{www}$.infogremiales.com.ar/noticia.php?n=61621

${ }^{57 h t t p s: / / w w w . p a g i n a 12 . c o m . a r / 255886-t e c h i n t-e c h o-a-1450-e m p l e a d o s ~}$ 
ellas comenzaron a utilizar la excepción estipulada para avanzar con suspensiones y reducciones salariales, contando con la homologación del Ministerio de Trabajo. La conflictividad laboral comenzó a orientarse en un sentido defensivo para los/as trabajadores/as, enfrentando la iniciativa empresarial por transferir los costos de la crisis en la mayor medida posible. Las disputas, entonces, se orientaron principalmente contra despidos, suspensiones y recortes salariales de diferentes tipos. Se destaca que en este período comenzó a tener una mayor relevancia la participación de sindicatos nacionales por rama, los cuales a través de diferentes instancias de negociación colectiva con cámaras empresariales y la homologación del Ministerio de trabajo, acordaron en términos generales suspensiones y recortes salariales, que sin embargo, fueron discutidas en muchos casos por seccionales y organizaciones de trabajadores/as de base. El salto cualitativo registrado por diferentes relevamientos en la cantidad de despidos, suspensiones y rebajas salariales puso en duda abiertamente la eficacia del decreto de "prohibición de despidos y suspensiones". En términos de la evolución de la pandemia en el período, al final del mismo, el 26 de abril, las víctimas fatales totales sumaban 185 en total en todo el país y el total de personas contagiadasdesde el inicio de la pandemia en todo el país era de 3.780.58

La cuantificación exacta de los despidos y de otras formas de afectación de las relaciones laborales en esta etapa está aún en proceso de análisis y hay distintas aproximaciones y fuentes que sólo podrán ser revisadas brevemente aquí, en función del eje principal de conflictividad. El informe oficial sobre la "Situación y evolución del trabajo registrado", publicado por el Ministerio de Trabajo de la Nación Argentina el 5 de junio de 2020 indica que "la información que surge de la Encuesta de Indicadores Laborales (EIL) para el mes de abril y del Sistema Integrado Previsional Argentino (SIPA) para el mes de marzo refleja con claridad el impacto de la pandemia en el trabajo registrado, interrumpiendo así, la incipiente recuperación que se había vislumbrado en febrero", resaltando que el trabajo registrado se contrajo en la mayoría de sus modalidades, incluyendo el empleo asalariado en empresas privadas. Esto se verificó en un contexto en el cual, en abril de 2020, según la EIL, el 19\% del total de las empresas relevadas no operó y el 38\% de las firmas operó a menos del $50 \%$ de su capacidad productiva.En marzo de 2020, se registraron 105 mil trabajadores registrados menos en relación a febrero $(-0,9 \%)$, y los asalariados del sector privado (-48 mil, $0,8 \%)$ y los monotributistas (-45 mil, $-2,8 \%$,) fueron las principales categorías que explicaron la caída. Al mismo tiempo, señala que también según la EIL, en abril de 2020, el nivel de empleo registrado del sector privado tuvo una caída de 0,6\% en relación al mes anterior, lo que constituye la mayor caída mensual desde la crisis del año 2002. En cuanto a la tasa de suspensiones, se ubicó en abril en el $7,5 \%$ cada 100 trabajadores, mostrando el nivel más alto de la serie, mientras que a

58 https://www.clarin.com/sociedad/casos-de-coronavirus-hoy-en-argentina-cuantos-muertos-hayy-como-avanza-la-pandemia-al-26-de-abril_0_UXLvxySQy.html 
nivel de empresa el 14\% aplicó suspensiones, más que duplicando los valores históricos.$^{59} \mathrm{El}$ último informe disponible del Ministerio de Trabajo, publicado en julio de 2020, indica que enmayo de 2020 la totalidad de las actividades redujeron el nivel del empleo registrado, encomparación con el mes anterior.El sector con mayor caída fue la construcción, que tuvo una reducción del 1,5\% en relación al mes anterior y del $21 \%$ en relación a mayo de 2019 . El comercio y los servicios financieros y a las empresas contrajeron su personal en un $0,6 \%$ en relación a abril de este año, mientras que la industria manufacturera lo hizo en un $0,3 \%$, mostrando un comportamiento algo menos contractivo que en marzo y abril, cuando tuvo caídas de $0,5 \%$. La pérdida interanual en el empleo en la industria alcanzó al 3\% y en el comercio al 3,4\%. Los servicios comunales, que incluyen salud y educación, también tuvieron este mes una reducción del empleo $(-0,1 \%)$ aunque menor a la del mes anterior $(-0,4 \%){ }^{60}$

Otros informes intentaron otras aproximaciones al impacto del ASPO en el mercado de trabajo, como el informe del Centro de Economía Política Argentina (CEPA) del 20 de abril de 2020, que propone una cuantificación. Allí se afirma que, entre el 15 de marzo y el 15 de abril, fueron detectados 12.609 trabajadores/as con "ruptura o riesgo de ruptura del contrato laboral" (5.386 despidos, 7.223 suspensiones) y 297.063 casos de trabajadores/as con "riesgo salarial", de los cuales 3070 corresponde a atraso de pago de sueldos, 54.030 a reducciones salariales, 8.480 a suspensiones con reducción salarial y 231.483 a acuerdos entre gremio y patronal para reducción salarial. Los 154 hechos relevados afectaron a 309.672 trabajadores/as.

Cuadro 2. Cantidad de trabajadores según tipo de afectación entre marzo y abril 2020

\begin{tabular}{|l|r|r|}
\hline & Cantidad & $\%$ \\
\hline Cambio o ruptura del contrato laboral & $\mathbf{1 2 . 6 0 9}$ & $\mathbf{4 , 0 7}$ \\
\hline Despidos & 5.386 & 1,74 \\
\hline Suspensiones & 7.223 & 2,33 \\
\hline Perjuicios laborales & $\mathbf{2 9 7 . 0 6 7}$ & $\mathbf{9 5 , 9 3}$ \\
\hline Atraso salarial & 3.070 & 0,99 \\
\hline Reducción salarial & 54.030 & 17,45 \\
\hline
\end{tabular}

\footnotetext{
${ }^{59}$ Ministerio de Trabajo de la Nación Argentina, Informe "Situación y evolución del trabajo registrado", $\quad 5$ de junio de 2020 http://www.trabajo.gob.ar/downloads/estadisticas/reportelaboral/Reporte_Laboral_Junio_2020.p df

${ }^{60}$ Ministerio de Trabajo de la Nación, Informe “Empleo registrado del sector privado a partir de los datos de la Encuesta de Indicadores Laborales para Mayo de 2020", Julio de 2020. Disponible en: http://www.trabajo.gob.ar/downloads/estadisticas/eil/eil_2005_informe.pdf
} 


\begin{tabular}{|l|r|r|}
\hline Suspensión con reducción salarial & 8.480 & 2,74 \\
\hline Reducción con acuerdo gremial & 231.483 & 74,75 \\
\hline TOTAL & $\mathbf{3 0 9 . 6 7 6}$ & $\mathbf{1 0 0 , 0 0}$ \\
\hline
\end{tabular}

Fuente: Elaboración propia en base a CEPA, 20/4/2020.

En el desagregado, afirman que los casos de ruptura o riesgo de ruptura contractual (despidos y suspensiones) se duplicaron y los casos de "riesgo salarial" experimentaron un crecimiento significativo durante la primera quincena de abril. En relación a sectores, identifican que el sector de servicios abarcaba el $58 \%$ de los/as trabajadores/as afectados por despidos y suspensiones en el sector privado (encabezando el rubro de la construcción), mientras que en situaciones de lo que denominan "riesgo salarial" el sector de la industria concentraba el $79 \%$ de los/as trabajadores/as afectados (centralmente sectores metalúrgicos, automotriz e hidrocarburos). En relación al rol de la intervención sindical, el informe destaca que en la mitad de los hechos relevados poseen información sobre la intervención sindical, y en el 87\% de esos casos el gremio ha intervenido en el conflicto, aunque no se especifica con qué resultados. ${ }^{61}$

El "Observatorio de Despidos durante la Pandemia" de La Izquierda Diario ${ }^{62}$ realizó otro relevamiento cuantitativo basado en noticias nacionales y locales y en denuncias recibidas, registrando desde mediados de abril un salto cualitativo en la cantidad de trabajadores/as afectados por despidos, suspensiones y rebajas salariales. ${ }^{63}$ Según el informe del 27 de abril, se registraron hasta entonces y desde el inicio del ASPO 8.876 despidos (2,35\% del total), 65.712 suspensiones $(17,42 \%$ del total), 176.342 trabajadores/as afectados por rebajas salariales $(46,73 \%$ del total) y 126.402 trabajadores/as afectados por suspensiones y rebajas salariales en conjunto $(33,50 \%$ del total $) .{ }^{64}$

\footnotetext{
${ }^{61}$ CEPA, "El impacto del aislamiento en el mercado de trabajo", 20 de abril de 2020. Disponible en: https://www.centrocepa.com.ar/informes/249-el-impacto-del-aislamiento-en-el-mercado-detrabajo-cuantificacion-de-despidos-suspensiones-y-reducciones-salariales-entre-el-15-de-marzoy-el-15-de-abril.html

${ }_{62}$ El Observatorio de Despidos durante la Pandemia de La Izquierda Diario (ODP-LID) es una iniciativa que surge de un grupo de sociólogas y sociólogos junto con estudiantes de sociología de las Universidades Nacionales de La Plata y Buenos Aires que cuenta con el asesoramiento de la investigadora Paula Varela (CONICET-UBA). Para más información: http://www.laizquierdadiario.com/Que-es-el-Observatorio-de-Despidos-durante-la-Pandemia

${ }^{63} \mathrm{http}$ ://www.laizquierdadiario.com/Son-mas-de-320-000-los-trabajadores-afectados-por-despidossuspensiones-y-rebajas-salariales

${ }^{64} \mathrm{http}: / /$ www.laizquierdadiario.com/Son-mas-de-375-000-los-trabajadores-afectados-por-despidossuspensiones-y-rebajas-salariales
} 


\section{Cuadro 3. Cantidad de trabajadores según tipo de afectación}

\begin{tabular}{|c|c|c|}
\hline & $\begin{array}{l}\text { Cantidad de } \\
\text { trabajadores }\end{array}$ & $\%$ \\
\hline Despidos & 8.876 & 2,35 \\
\hline Suspensiones & 65.712 & 17,42 \\
\hline Rebajas salariales & 176.342 & 46,73 \\
\hline $\begin{array}{c}\text { Rebajas salariales y } \\
\text { suspensiones }\end{array}$ & 126.402 & 33,5 \\
\hline Total & 377.332 & 100,00 \\
\hline
\end{tabular}

Fuente: Elaboración propia en base al "Observatorio de Despidos durante la Pandemia", $27 / 4 / 2020.65$

En lo que se refiere a los procesos más significativos de la etapa, cabe señalar que un primer grupo de empresas continuaría con suspensiones decididas de manera unilateral, en muchos casos otorgando sumas no remunerativas que sólo compensarían parte de la retribución habitual de los/as trabajadores/as, dejando afuera adicionales y premios que figuran en convenios. Hemos visto esta situación tempranamente en el caso de SIAT Valentín Alsina, del grupo Techint y también en Ledesma, del grupo Blaquier, que habilitó la suspensión de los/as trabajadores/as que se desempeñan en la fabricación de papel por el pago de una asignación no remunerativa equivalente al $70 \%$ del salario neto anteriormente percibido. ${ }^{66}$

En otros casos, diversos trabajadores/as denunciaron a los empleadores/as por la falta de pago total o parcial de salarios correspondientes al mes de marzo, o el fraccionamiento de su salario en cuotas. El 8/04 se conoció públicamente el caso de los trabajadores del frigorífico Penta, en Quilmes, que fueron reprimidos por

\footnotetext{
${ }^{65}$ El Observatorio de Despidos durante la Pandemia de La Izquierda Diario (ODP-LID) realiza el relevamiento de despidos, suspensiones y bajas salariales a partir de un relevamiento de fuentes de prensa nacionales, regionales y locales. De acuerdo a su explicitación metodológica relevan los siguientes medios nacionales: La Nación, Clarín, Página/12, Tiempo Argentino, Crónica, La Izquierda Diario, Infogremiales, El Cronista, Izquierda Web, Prensa Obrera. En términos de los medios locales: El Día (La Plata); Pulso Noticias (La Plata), La Capital (Mar del Plata), El Tribuno (Jujuy), Nuevo Diario (Salta), La Gaceta (Tucumán), Diario Uno (Mendoza); Los Andes (Mendoza); La Capital (Santa Fé); El Litoral (Santa Fé); La Voz (Córdoba); Hoy Día (Córdoba); Lmneuquén (Neuquén); Diario Río Negro (Río Negro); El Litoral (Corrientes); El Esquiu (Catamarca); Diario Norte (Chaco); El Diario (Entre Ríos); La Mañana (Formosa); La Rioja (La Rioja); El Chubut (Chubut); Primera Edición (Misiones); Tiempo de San Juan (San Juan); El Diario de La Pampa (La Pampa); Diario de La República (San Luis); Nueva Diario Web (Santiago del Estero); Diario Prensa (Tierra del Fuego); Opinión Austral (Santa Cruz), ODP-LID Santa Fe; ODP-LID Mendoza: ODP-LID Tucumán más denuncias recibidas en LID.
}

${ }^{66} \mathrm{http}: / /$ infogremiales.com.ar/noticia.php? $\mathrm{n}=61957$ 
las fuerzas policiales cuando realizaban una concentración pacífica en la puerta del establecimiento laboral para denunciar que no habían cobrado la segunda quincena de marzo y no recibían los aportes a las obras sociales, que el dueño de la empresa estaba haciendo de hecho un lockout patronal, al no dejar ingresar a los trabajadores a la planta, y que habían recibido un pedido de desafuero toda la comisión interna y otros 20 trabajadores del establecimiento telegramas de despido. ${ }^{67}$ Los trabajadores denunciaron que Ricardo Bruzzese, dueño del frigorífico, estaba buscando quebrar la firma y arrancar de nuevo con un plantel de trabajadores sin antigüedad. ${ }^{68}$ La Federación de Trabajadores de la Carne (FETSICARA) convocó a un paro de 24 horas para el lunes siguiente, en repudio a estos hechos. A pesar de la intervención del Ministerio de Trabajo, que dictó la conciliación obligatoria, y de distintas marchas que los trabajadores y sus familias protagonizaron para continuar el reclamo ${ }^{69}$, con ollas populares en la puerta del establecimiento, no huborespuestas por parte del empresario hasta la actualidad.

Denuncias de despidos masivos se registraron hasta entonces en empresas tercerizadas de seguridad, en transporte de pasajeros, en actividades ligadas al comercio, a la gastronomía, a la energía y la construcción y al servicio de salud.70 En este punto y como ya destacamos, serían punta de lanzalos despidos que Techint construcciones realizó a fines de marzo, los cuales fueron finalmente homologados el 6 de abril con el gremio de la construcción (UOCRA) y el Ministerio de trabajo, luego de que la empresa apelara a una cláusula de la ley 22.250 del sector sobre "fuerza mayor por paralización de obras" y al amparo dado por el artículo 223 bis de la LCT. ${ }^{71}$

Por último, en una cantidad de casos creciente se verificó una reacción por parte de las dirigencias de las organizaciones sindicales por rama. Durante este período se dieron una serie de negociaciones llevadas adelante por organizaciones sindicales por rama de actividad y cámaras empresariales que realizaron fuertes presiones para acordar diversas modalidades de suspensiones con rebajas salariales. El Sindicato de Mecánicos y Afines del Transporte Automotor (SMATA) acordó el licenciamiento del personal de las grandes

67 https://www.anred.org/2020/04/09/frigorifico-penta-tras-la-represion-convocan-a-cese-deactividades-en-todo-el-pais/

68 https://www.anred.org/2020/04/19/entrevista-a-angel-mileo-delegado-del-frigorifico-penta-nosomos-ingenuos-sabemos-que-un-comisario-no-llama-por-telefono-y-aparecen-300-policias/

69 http://www.laizquierdadiario.com/Fotogaleria-Los-trabajadores-de-Penta-se-movilizaron-aCasa-Rosada

${ }^{70}$ Observatorio del Derecho Social-CTAA, "El trabajo en la cuarentena - Evaluación del estado de las relaciones laborales a un mes de dictado el aislamiento, social, preventivo y obligatorio", 28 de abril de $2020 . \quad$ Disponible en: https://www.agenciacta.org/IMG/pdf/El_trabajo_en_la_cuarentena__Informe_ODS_CTAA_28_de_abril.pdf

${ }^{71}$ https://www.tiempoar.com.ar/nota/techint-ratifico-el-despido-de-1450-empleados 
automotrices con el pago del 70\% del sueldo bruto el 17/04. ${ }^{72}$ El 20/04 el sindicato de petróleo y gas privado de Neuquén, Río Negro y La Pampa, y el Sindicato del Petróleo y Gas Privado del Chubut acordaron suspensiones al 50\% del salario para 32.000 trabajadores/as de yacimientos que estaban sin tareas desde la declaración del ASPO. ${ }^{73}$

Las negociaciones de las cúpulas sindicales no estuvieron exentas de una conflictividad desarrollada por los trabajadores/as. La Asociación Obrera Textil (AOT) acordó con la cámara empresaria del sector el 27/04 el pago de sumas fijas durante tres meses para los/as trabajadores/as que en el marco del ASPO no estuvieran cumpliendo sus jornadas laborales. ${ }^{74}$ En el mismo momento, trabajadores/as textiles de Trelew se movilizaron masivamente rompiendo la cuarentena y cuestionando los recortes salariales acordados por la organización sindical junto a la federación de empresarios ${ }^{75} \mathrm{La}$ UOM se prestaba, a partir de negociaciones llevadas adelante por el Secretario General Antonio Caló, a firmar un acuerdo que garantizara la generalización de suspensiones y la reducción de un $30 \%$ de los salarios ${ }^{76}$, pero la protesta de distintas seccionales del gremio lo impidió. ${ }^{77}$ La oposición provino centralmente de los/as trabajadores/as de algunas de las grandes empresas siderúrgicas, que son el entramado central de esta actividad económica, y venían peleando desde las plantas de producción contra los intentos patronales por suspender, rebajar salarios, y en algunos casos, intentar que se vuelva a producir.

En este contexto, el 12 de abril una larga lista de organizaciones sindicales expresaron su preocupación en un documento titulado "Nadie se salva solo" en el que afirmaban que "las medidas tomadas por el Gobierno nacional para proteger el empleo y el salario parecieran no aplicarse a un gran sector del empresariado que despide, suspende y rebaja salarios desconociendo los decretos de emergencia y la legislación laboral." Marcando la importancia de los controles y sanciones, exigían la implementación de estrictos protocolos de protección, el desarrollo de políticas adicionales para la protección de los trabajadores de la "economía popular", ampliando la cobertura y extendiéndolas en el tiempo, y

\footnotetext{
72 https://www.infobae.com/politica/2020/04/17/el-gremio-mecanico-pacto-con-las-autopartistaslas-suspensiones-con-el-pago-de-un-70-del-sueldo/

$73 \mathrm{https} / / /$ www.infobae.com/politica/2020/04/21/dos-sindicatos-petroleros-aceptaron-suspensionescon-una-rebaja-salarial-del-50/

${ }^{74} \mathrm{https} / /$ www.ambito.com/economia/trabajadores/gremio-textil-acuerda-suma-fija-17000-y-20000los-que-no-estan-trabajando-n5098602

${ }^{75 h t t p s: / / w w w . e l c o h e t e a l a l u n a . c o m / e l-q u i n t o-m a n d a m i e n t o-n o-t i e n e-s e l l o / ~}$

76 https://estadodealerta.com.ar/uom-acordo-rebajas-salariales-del-30-para-metalurgicos-y-5000suspensiones-en-siderar/

77 https://estadodealerta.com.ar/rebelion-en-la-granja-metalurgica-desoyen-acuerdo-de-calo-conreduccion-de-salarios/
} 
demandando la declaración del COVID-19 como enfermedad ocupacional, lo que se concretó un día después. ${ }^{78}$

Además de las situaciones de conflictividad derivadas de despidos, suspensiones y las diversas modalidades de "ataques" salariales que durante este período tomaron la delantera, la disputa por el cumplimiento de medidas de salubridad efectivas para prevenir contagios continuó en el caso de los/as trabajadores/as que siguieron desarrollando tareas durante este período. Un paso fundamental en este marco fue el Decreto de Necesidad y Urgencia 367 del 13 de abril de 2020 que estableció al COVID-19 como una enfermedad ocupacional, indicando que al tomar conocimiento de la denuncia del "infortunio laboral", acompañada del correspondiente diagnóstico emitido por entidad sanitaria, las aseguradoras de riesgos del trabajo (A.R.T.) no podrán rechazar la cobertura de esta contingencia y deberán brindar en forma inmediata, las prestaciones previstas en la Ley $\mathrm{N}^{\circ} 24.557$ y sus normas modificatorias y complementarias. ${ }^{79}$

En lo que se refiere a las protestas, el sector de trabajadores/as de reparto y "delivery" urbano considerado esencial durante la pandemia, está caracterizado por altos niveles de precariedad contractual en el mejor de los casos (en el caso de la economía de plataformas sin relación contractual laboral) y bajos salarios, y cuenta con una altísima proporción de mano de obra migrante. Los/as trabajadores/as de las principales empresas del rubro (Glovo, Rappi y Pedidos Ya), que se encuentran obteniendo fuertes ganancias por el crecimiento de la actividad durante la pandemia, reclaman desde los primeros días del ASPO por la entrega de implementos de higiene y seguridad, por un seguro para accidentados y licencias para quienes estuvieran enfermos/as, por una compensación salarial por trabajo durante la cuarentena obligatoria, y por la regularización de su situación laboral. El 22/04 (se repitió el 08/05) fue convocado un paro, con protesta y movilización, por agrupaciones del sector como Glovers Unidos Argentinos y la Agrupación de Trabajadores de Reparto, mientras que el sindicato que aún busca su formalización, la Asociación de Personal de Plataformas (APP), se declaró en "estado de alerta" y llamó a apoyar "toda manifestación de repartidores que se haya realizado y se vaya a realizar durante la cuarentena". ${ }^{80}$

Se realizaron también diferentes reclamos relacionados al accionar patronal frente a la presencia de casos de COVID-19 en la plantilla de trabajadores/as y los

\footnotetext{
${ }^{78}$ Solicitada "Nadie se salva solo" firmada por sindicatos aceiteros, portuarios, navales, ceramistas, gráficos, estatales, de la energía, docentes, del azúcar, telefónicos, gastronómicos, comercio, correo, del cuero, entre muchos otros.

${ }^{79}$ Esto fue considerado un importante avance, aunque desde organizaciones como la Asociación de Abogados y Abogadas laboralistas señalaron algunos aspectos del DNU que ameritan revisión y ampliación.Ver: http://www.aal.org.ar/2020/04/16/el-dnu-367-2020-y-el-covid-19como-enfermedad-profesional/

80 https://www.lanacion.com.ar/economia/paro-repartidores-trabajadores-reclaman-mas-ingresosmejores-nid2356876;https://www.pagina12.com.ar/264507-coronavirus-paro-de-repartidores; http://www.laizquierdadiario.com/Repartidores-de-aplicaciones-al-paro-por-nuestros-derechos
} 
protocolos de seguridad aplicados. Particularmente, en la industria frigorífica se dieron una serie de graves denuncias y situaciones de conflictividad por la insalubridad de las condiciones de trabajo. En el caso del frigorífico El Federal, situado en la intersección entre Quilmes, Florencio Varela y Berazategui, falleció un trabajador veterinario del SENASA en la planta por COVID 19 y se suscitaron contagios masivos entre otros 9 trabajadores y sus familiares. Los/as trabajadores/as y vecinos se movilizaron reclamando la clausura de la planta y el pago de licencias. El frigorífico fue clausurado dos veces por las autoridades (la segunda, tras una reapertura de facto realizada por el dueño con un falso amparo judicial) y el empresario finalmente detenido, tras haber sido denunciado penalmente ${ }^{81}$ En el sector de comercio, particularmente en locales de la cadena de supermercados COTO, se reiteraron reclamos por incumplimientos patronales en las medidas y protocolos de higiene y seguridad, y por reiterados intentos de la empresa por ocultar casos de trabajadores/as de la plantilla que presentaban síntomas de COVID-19 y continuaban yendo al espacio de trabajo. Los/as trabajadores/as realizaron denuncias públicas y, en una de las sucursales, abandonaron sus puestos exigiendo al gerente de Recursos Humanos el cumplimiento de las medidas sanitarias y la provisión de elementos de seguridad..$^{82}$

En relación al teletrabajo, modalidad que se extendió de distintas maneras en diferentessectores desde el principio del aislamiento, agrupaciones y gremios marcaron la necesidad de regular el régimen de trabajo y dar cobertura a los/as trabajadores/as. Particularmente, en el sector docente de todos los niveles, se dieron pronunciamientos de organizaciones sindicales de la educación como Ademys contra las presiones para que los docentes evalúen procesos de aprendizaje en este contexto, de Conadu Histórica y UTE exigiendo límites a la realización de trabajo docente a distancia, y de distintas agrupaciones reclamando por el avasallamiento de condiciones laborales, las dificultades existentes para garantizar el desarrollo de actividades en forma no presencial ${ }^{83}$, y la necesidad de que se otorguen licencias por cuidado a profesores/as universitarios. ${ }^{84}$ En el sector

81 http://www.laizquierdadiario.com/El-Federal-necesitamos-testeos-licencias-pagas-y-elresguardo-de-las-fuentes-de-trabajo. Tercer reporte del equipo Covid-19 en la Región Sanitaria VI (Instituto Gino Germani - Facultad de Ciencias Sociales, UBA), "Trabajadores de la región sanitaria VI en el contexto del Covid 19". Disponible en: https://medium.com/@Covid19RegionSanitariaVI/tercer-reportebe679da4d30a.https://www.elcohetealaluna.com/un-cuadro-a-lo-guernica/

82http://www.enorsai.com.ar/politica/29625-covid-en-los-supermercados.html

83 https://www.anred.org/2020/04/06/parar-la-pelota-trabajo-en-la-universidad-en-tiempos-depandemia/

${ }^{84} \mathrm{https} / / / \mathrm{www}$.anred.org/2020/04/12/reclaman-licencias-por-cuidado-para-docentes-universitarixs/; https://www.facebook.com/notes/unida-docentes-universitarixs-de-la-uba-en-rompiendocadenas/pandemia-virtualizaci\%C3\%B3n-forzosa-y-flexibilizaci\%C3\%B3n-laboral 
de judiciales de la provincia de Buenos Aires, la Asociación Judicial Bonaerense logró un inédito acuerdo paritario que fijó condiciones para esta modalidad laboral: reguló la jornada de trabajo, estableció su carácter extraordinario, voluntario y revocatorio, y fijó pautas de control del proceso de trabajo porla organización sindical. ${ }^{85}$

En relación a los/as trabajadores/as de salud, señalamos en la etapa previa que había sido uno de los sectores que rápidamente inició demandas en relación a las condiciones en que se desarrolla su labor. En una gran mayoría de hospitales del país los/as trabajadores/as continuaron alertando sobre la falta de elementos de protección personal y de insumos para la atención; y reclamando por mayor personal y la regularización de los contratados/as bajo modalidades precarias. En algunos casos han sido las organizaciones sindicales y los propios trabajadores/as quienes se han tenido que abastecer de recursos ante la falta de garantía por parte de los empleadores, tanto estatales como privados. En las últimas semanas de marzo, se extendieron las denuncias y los reclamos en relación al ocultamiento y las pocas acciones por parte de las autoridades de hospitales y clínicas para enfrentar la propagación del virus entre trabajadores/as de la salud. ${ }^{86}$

\section{Cuarto período: 27 de abril - 10 de mayo}

El 28 de abril se firmó un acuerdo entre una de las principales centrales empresarias (Unión Industrial Argentina -UIA) y la principal central obrera (Confederación General del Trabajo - CGT), homologado por el Ministerio de Trabajo, en el que se estipuló que los trabajadores suspendidos cobrarían no menos del $75 \%$ de su salario neto en abril y mayo. La homologación de la cartera laboral sería automática para los casos que cumplan ese requisito. El acuerdo no distinguió tamaño o rentabilidad de las empresas, y estableció que si el gobierno nacional asignara algún tipo de ayuda monetaria posterior ella debería ser descontada de la parte abonada por el empleador. Este convenio constituyó un punto de inflexión en tanto institucionalizó y legalizó una estrategia que ya venían aplicando de facto muchas grandes empresas, como vimos en el período previo, y habilitó que las suspensiones y los recortes salariales se generalicen en otros sectores; en algunos casos a través de instancias de negociación colectiva por sector homologadas por el Ministerio de Trabajo y en otros por avance de hecho de las direcciones empresariales. En términos de la evolución de la pandemia en el período, al final del mismo, el 10 de mayo, las víctimas fatales totales sumaban

\footnotetext{
${ }^{85} \mathrm{https} / / /$ pulsonoticias.com.ar/67267/teletrabajo-asociacion-judicial-bonaerense-convenio/

${ }^{86}$ Observatorio del Derecho Social-CTAA, "El trabajo en la cuarentena - Evaluación del estado de las relaciones laborales a un mes de dictado el aislamiento, social, preventivo y obligatorio", 28 de abril de 2020. Disponible en https://www.agenciacta.org/IMG/pdf/El_trabajo_en_la_cuarentena__Informe_ODS_CTAA_28_de_abril.pdf
} 
305 en total en todo el país y el total de personas contagiadasen todo el país desde el inicio de la pandemia era de6.034. ${ }^{87}$

En este contexto, la conflictividad a nivel de seccionales y lugares de trabajo no desapareció, aunque continuó desarrollándose centralmente en torno a despidos, suspensiones y recortes salariales. También durante esta etapa, con el aumento exponencial de contagios en las villas de emergencia, se visibilizó la intensificación de las tareas comunitarias llevadas adelante mayoritariamente por mujeres en los barrios, y se desarrollaron importantes protestas y movilizaciones desde organizaciones sociales en torno al reclamo por alimentos y asignaciones para los/as trabajadores/as no registrados/as.

El informe realizado por el Equipo de Estudio sobre sindicalismo, conflicto y territorio (CEIL-CONICET), publicado el 11 de mayo ${ }^{88}$ y basado en encuestas autoadministradas realizadas por delegados/as y activistas sindicales durante el mes de abril en el sector público, servicios, comercio e industria, resaltó que, del total de casos, un 9\% denunciaba haber sufrido despidos en sus lugares de trabajo, un $24 \%$ suspensiones y disminución salarial, y un $32 \%$ desregulación de obligaciones patronales (licencias, cambios en la jornada laboral, etc.). En la división por sectores, la industria presentaba un mayor índice de "vulnerabilidad", con mayor presencia de despidos, suspensiones y distintas formas de desregulación laboral. Por su parte, un nuevo informe del ODS-CTAA señaló que a partir del acuerdo UIA-CGT las suspensiones con pago de una contraprestación no remunerativa se generalizaron, quintuplicando los máximos porcentajes registrados desde que el Ministerio de Trabajo comenzó a relevar esa variable en $2006 .{ }^{89}$

El acuerdo CGT-UIA se dio luego de que, durante el período previo, se desarrollaran negociaciones entre cámaras empresariales y sindicatos de rama de importancia a nivel nacional. Estas continuaron durante esta etapa. El mismo día del acuerdo general, la UOM firmó su propio acuerdo de suspensiones. Tras la presión proveniente de las seccionales y las comisiones internas de muchas empresas, y el fracaso de las negociaciones previas, el acuerdo se situó en un piso

\footnotetext{
87 https://www.lanacion.com.ar/sociedad/coronavirus-hoy-argentina-mundo-minuto-minutonovedades-nid2363935

${ }^{88}$ Informe "La situación del empleo en Argentina durante el aislamiento social, preventivo y obligatorio por la pandemia COVID-19", del 11 de mayo de 2020. Disponible en: http://www.ceil-conicet.gov.ar/2020/05/informe-la-situacion-del-empleo-en-argentina-duranteel-aislamiento-social-preventivo-y-obligatorio/informe-ceil-el-empleo-en-la-argentina-en-elmarco-del-aspo/

${ }^{89}$ Observatorio del Derecho Social-CTTA, "Negociación colectiva 2020: revisiones, aumentos y suspensiones", 24 de julio de 2020. Disponible en: http://ods.ctaautonoma.org.ar/wpcontent/uploads/2020/07/Negociaci\%C3\%B3n-colectiva-2020-Primer-semestre.pdf
} 
salarial del 86\% del salario neto para los suspendidos/as por cuatro meses ${ }^{90}$ El 5 de mayo el sindicato de comercio, el más numeroso del país, acordó con las cámaras empresarias de la rama suspensiones por sesenta días de unos 800.000 trabajadores/as mercantiles con el pago de salarios netos al 75\%. ${ }^{91} \mathrm{El} \mathrm{mismo} 28$ de abril, la Unión de Trabajadores del Turismo, Hoteleros y Gastronómicos (UTHGRA) había acordado con las cámaras empresarias del sector hotelero suspensiones al $75 \%$ del salario neto por 60 días..$^{92} \mathrm{El} 08$ de mayo, la UOCRA firmó un acuerdo con las cámaras empresariales del sector de la construcción para reducir el salario neto de los/as trabajadores suspendidos/as al $75 \% .{ }^{93}$ Estos recortes salariales se combinaron con una inflación que continuó horadando el poder adquisitivo de los ingresos de los/as trabajadores/as y con un salario real que, en promedio para el sector privado, retomó su declive luego de los incrementos registrados durante enero y febrero. ${ }^{94}$

Sin embargo, hay que destacar que a partir de mayo comenzaron a impulsarse negociaciones en distintas actividades, como las ligadas a la alimentación y a los medicamentos, que dieron cuenta que la emergencia no constituye de por sí un obstáculo para la renovación de acuerdos salariales vencidos. En este marco, se concluyeron en forma exitosaalgunas paritarias con términos radicalmente distintos a los expuestos previamente, como la de la Federación de Trabajadores del Complejo Industrial Oleaginoso, Desmotadores de Algodón y Afines de la República Argentina. El acuerdo paritario firmado el 30 de abril de 2020 elevó un $25 \%$ el salario básico inicial, garantizó una suma retroactiva por los meses de enero a abril e incluyó una cláusula de revisión pautada para el próximo mes de agosto, manteniendo el planteo de la organización del derecho a un Salario Mínimo, Vital y Móvil según su definición en el artículo 14 bis de la Constitución Nacional y artículo 116 de la LCT, esto es, que asegure a los trabajadores "alimentación adecuada, vivienda digna, educación, vestuario, asistencia sanitaria, transporte y esparcimiento, vacaciones y previsión". ${ }^{95}$

La empresa aeronáutica Latam determinó suspender al personal y recortar compulsivamente los salarios al 50\% por tres meses, bajo el aval del artículo 223 bis de la LCT, citado por el mismo decreto gubernamental de "prohibición de despidos y suspensiones". La Asociación del Personal Aeronáutico (APA)

90 https://www.ambito.com/economia/cuarentena/la-uom-firmo-su-propio-acuerdo-suspensionesal-86-y-cuatro-meses-n5098908

91 https://www.infobae.com/politica/2020/05/06/unos-800000-empleados-de-comercio-seransuspendidos-con-la-rebaja-salarial-del-25/

92 https://www.infobae.com/politica/2020/04/29/oleada-de-suspensiones-mas-de-1200000trabajadores-tendran-un-descuento-salarial-del-25-durante-60-dias/

${ }^{93} \mathrm{http} / / /$ www.uocra.org/pdf/ba18b7_acuerdoART_223bis_en76-75.pdf

${ }_{94}$ Observatorio del Derecho Social-CTTA, "Negociación colectiva 2020: revisiones, aumentos y suspensiones", 24 de julio de 2020. Disponible en: http://ods.ctaautonoma.org.ar/wpcontent/uploads/2020/07/Negociaci\%C3\%B3n-colectiva-2020-Primer-semestre.pdf ${ }^{95} \mathrm{http}: / /$ federacionaceitera.com.ar/2020/04/30/acuerdo-en-la-paritaria-salarial-aceitera-3/ 
condenó y desmintió a la empresa. ${ }^{96}$ En la planta de La Tablada de la siderúrgica Acindar (del grupo Arcelor Mittal) la empresa concretó el 30/04 el despido selectivo de 6 trabajadores contratados y rebajó hasta el $40 \%$ de los salarios de operarios de planta. ${ }^{97}$ En un comunicado conjunto la seccional La Matanza de la UOM, la comisión interna y el cuerpo de delegados de la planta rechazaron los despidos, exigieron a la empresa que retrotraiga la medida por ser ilegal y condenaron la rebaja de salarios por ser superior a lo acordado por la UOM y las cámaras empresariales.$^{98} \mathrm{La}$ seccional local fue la única en oponerse al acuerdo definitivo firmado a nivel nacional por la UOM..$^{99}$

Los/as trabajadores/as de la salud tanto en el ámbito público como privado continuaron reclamando, como desde el principio de la pandemia, por elementos de protección personal (ambos, calzados de seguridad, protecciones faciales, barbijos, etc.), a lo que se sumaron en esta etapa conflictos por despidos y reducciones salariales arbitrarias. ${ }^{100} 101102 \mathrm{El} 7$ de mayo, tras conocerse que Argentina es uno de los países con mayor tasa de infectados en el personal de salud, distintas organizaciones gremiales del sector realizaron una jornada nacional de lucha, con paros y marchas, en reclamo del cobro del bono estímulo de $\$ 5000$ durante cuatro meses, la exención en el pago de impuesto a las ganancias, la protección de agentes sanitarios con cantidad y calidad de equipos personales y la apertura de paritarias. ${ }^{103}$

Durante esta etapa, la ofensiva empresarial comenzó a ir más allá de los despidos, suspensiones y rebajas salariales, y apuntó a empezar a consolidar los impactos regresivos para los trabajadores aún en la vuelta a la actividad. El 6 de mayo los empresarios nucleados en la Asociación Empresaria Argentina (AEA) emitieron un comunicado de prensa en el que instaron a consolidar el regreso, de forma ordenada y con medidas de protección, al trabajo y la producción, para darle prioridad a mantener vivo el aparato productivo del país. ${ }^{104}$ En este sentido,

\footnotetext{
${ }^{96} \mathrm{http}: / / \mathrm{www}$.infogremiales.com.ar/noticia.php?n=62026v

97 http://www.laizquierdadiario.com/La-Matanza-despidos-y-rebajas-salariales-en-Acindar-LaTablada

98 https://www.matanzadigital.com.ar/confirmaron-despidos-en-acindar-y-se-profundiza-elconflicto/

99 https://www.infobae.com/politica/2020/05/02/no-comparto-que-les-bajen-el-sueldo-a-lostrabajadores-y-mucho-menos-a-los-metalurgicos-dijo-el-jefe-de-la-uom-la-matanza/

${ }^{100 h t t p s: / / w w w . e l c o h e t e a l a l u n a . c o m / e l-q u i n t o-m a n d a m i e n t o-n o-t i e n e-s e l l o / ~}$

101 https://www.anred.org/2020/05/03/tigre-el-intendente-zamora-despide-a-trabajadorasesenciales/; https://cicop.org.ar/seccionales-municipales/seccionales-municipales-200/ 102http://www.infogremiales.com.ar/noticia.php?n=62047

103 https://www.diariopopular.com.ar/general/mas-40-gremios-la-salud-ratificaron-la-jornadanacional-lucha-n475034

$104 \mathrm{https} / /$ www.infobae.com/economia/2020/05/06/los-empresarios-de-la-asociacion-empresariaargentina-le-reclamaron-al-gobierno-volver-a-producir-y-evitar-el-default/
} 
nuevamente el grupo Techint ya había dado el primer paso, desde el período previo. Tras presionar por distintas vías para retomar la producción en sus plantas siderúrgicas, se hizo público un acuerdo entre la UOM Campana y la empresa, en el que se afirmaba que mediante resolución del Ministerio de Trabajo de la Nación, se aprobó el "Plan de Producción” y el "Protocolo de Higiene, Salud y Seguridad COVID-19" presentado por la empresa a los efectos de retomar las tareas de producción a partir del 20 de abril en relación a actividades consideradas como esenciales en la pandemia (producción de tubos para almacenamiento de oxígeno medicinal, tubos para fabricación de materiales estructurales para máquinas agrícolas, y tubos para la industria petrolera). El sindicato exigió excluir a los/as trabajadores/as pertenecientes a grupos de riesgo y el estricto cumplimiento de los protocolos de higiene, salud y seguridad. ${ }^{105}$

Por su parte, desde principios de mayo se confirmó un aumento exponencial de casos de contagio de coronavirus en villas de emergencia en la Ciudad de Buenos Aires. Esto visibilizó no solo la situación de extrema precariedad en el acceso a la vivienda y la salud pública en los barrios pobres, y la imposibilidad de generar ingresos cotidianos para una buena parte de la sociedad que vive y trabaja por fuera de relaciones sociales asalariadas, sino también una brutal intensificación de las tareas de cuidado socializados a partir de la declaración del ASPO. ${ }^{106}$ Desde mediados de marzo se multiplicaron las ollas populares y la cantidad de personas que acude a los comedores, merenderos barriales, guarderías y cooperativas de cuidado a personas mayores, sostenidas fundamentalmente por organizaciones sociales y particularmente por mujeres. ${ }^{107}$ En relación a esto, durante mayo comenzaron a darse movilizaciones, protestas y cortes de organizaciones sociales que reclamaron, entre otras cosas, refuerzos en la asistencia alimentaria estatal, agua potable las $24 \mathrm{hs}$. en los barrios, un Ingreso Básico Universal, la aplicación de la ley de abastecimiento en relación a alimentos,

\footnotetext{
${ }^{105}$ Comunicado Unión Obrera Metalúrgica, seccional Campana-Zárate, 17 de abril de 2020.

${ }^{106}$ Una referente importante en esta tarea de visibilización de la falta de condiciones mínimas de vida y cuidado en las villas fue Ramona Medina, que había sido portavoz de las denuncias sobre las graves deficiencias del gobierno de la CABA, la falta de luz y agua, particularmente en la Villa 31, donde vivía y desarrollaba un vital trabajo comunitario con la organización "La Garganta Poderosa", y las condiciones dramáticas de falta de alimentación y asistencia del gobierno de Rodríguez Larreta. Ramona Medina murió por COVI-19 el 17 de mayo de 2020, estando su familia y muchos otros habitantes y referentes de la villa 31 también contagiados/as, muchos de ellos con consecuencias fatales: https://www.ambito.com/informacion-general/yason-7-los-referentes-barriales-fallecidos-coronavirus-n5109159

$107 \quad$ https://www.anred.org/2020/04/20/ollas-mujeres-y-feminismo-popular/; http://lanaciontrabajadora.com.ar/cuidados-en-pandemia/; https://www.anred.org/2020/04/01/radiografia-de-comedores-se-complejiza-la-situacion-en-losbarrios-populares/; https://www.anred.org/2020/04/07/el-hambre-de-siempre-mas-aislamientosocial/
} 
el pago sin restricciones del IFE y el incremento en los distintos programas sociales. ${ }^{108}$

Otro de los sectores esenciales que ha tenido visibilidad no sólo por la intensificación de sus tareas durante el ASPO sino también por la conflictividad en relación a las condiciones laborales, es el de las trabajadoras de la Línea 144 de asistencia por violencia de género. Las medidas de aislamiento social generaron un recrudecimiento de la violencia contra las mujeres, agravadas por la situación de encierro y crisis económica, que derivó en una intensificación de las labores de acompañamiento y cuidado en esta área estatal, que como otras en el Estado, se encuentra sostenida por formas de precarización laboral. Desde marzo las trabajadoras dependientes del Ministerio de Mujeres, Géneros y Diversidad de la Nación emitieron comunicados ante la situación de gravedad en la que se encuentran realizando su labor, denunciando la situación de precarización laboral, los salarios por debajo de la línea de pobreza, las condiciones edilicias "paupérrimas" de sus lugares de trabajo, la ausencia de elementos de higiene necesarios, la falta de personal y presupuesto, y la sobrecarga de tareas en el actual contexto. ${ }^{109}$ También las trabajadoras de la línea 144 dependientes del gobierno de la Ciudad de Buenos Aires realizaron un paro en la atención el 18 de mayo reclamando por atrasos en los haberes y las condiciones de precarización en su sector de trabajo. ${ }^{110}$

\section{Quinto período: 11 de mayo-25 de mayo}

En términos de la evolución de la pandemia en el período, al final del mismo, el 25 de mayo, las víctimas fatales totales sumaban 467 en total en todo el país y el total de personas contagiadasen todo el país desde el inicio de la pandemia era de12.628. ${ }^{11}$ Por Decreto 487/2020 el Poder Ejecutivo prorrogó el 18 de mayo la "prohibición de despidos y suspensiones", aunque la información disponible, todavía limitada, parece indicar quelos despidos, junto con las suspensiones y los recortes salariales, continuaron durante este período. Durante este período también resaltaron formas más extremas de ataques patronales como el lockout y las amenazas de traslado de producción a plantas de otros países, con las que

\footnotetext{
$108 \mathrm{http} / / /$ folweb.com.ar/nota/1362/los_motivos_por_los_cuales_comienzan_a_reactivarse_los_recl amos_sociales_en_la_calle/; https://www.anred.org/2020/05/18/organizaciones-sociales-retomanprotestas-por-alimentos-trabajo-y-la-crisis-sanitaria-en-caba/;

https://www.anred.org/2020/05/12/estamos-en-la-primera-linea-contra-el-hambre-pero-notenemos-las-cuestiones-elementales-para-una-

olla/http://folweb.com.ar/nota/1365/basta_de_extorsion_empresarial_y_basta_de_hambre_aplica cion_de_la_ley_de_abastecimiento_ya/

109https://pulsonoticias.com.ar/63676/linea-144-nacion-recargan-tareas/

${ }^{110} \mathrm{https} / / / \mathrm{www}$. tiempoar.com.ar/nota/paro-en-la-linea-144-de-asistencia-por-violencia-de-generode-la-ciudad

${ }^{111}$ https://argentina.as.com/argentina/2020/05/25/tikitakas/1590397597_735912.html
} 
algunas empresas intentaron asentar el fantasma de despidos masivos, en clara actitud de amedrentamiento para los/as trabajadores/as y a sus organizaciones gremiales. También durante esta etapa se dieron permisos para la reanudación progresiva de muchos sectores de la producción industrial, lo que derivó en disputas por contenidos y formas de los protocolos de higiene y seguridad a aplicar, y en relación al accionar frente a situaciones de contagios de trabajadores/as en los espacios de trabajo. Al mismo tiempo, se daría a conocer que grandes empresas que venían despidiendo y/o suspendiendo empleados/as se encontraban cobrando el subsidio estatal ATP para garantizar salarios de trabajadores/as e incluso gerentes.

En un comunicado del 18 de mayo titulado "Una reducción generalizada de los salarios avalada por el Ministerio de Trabajo de la Nación", la Asociación de Abogados Laboralistas condenó duramente el acuerdo entre la CGT y la UIA, y al Ministerio de Trabajo, por homologar decenas de acuerdos que reducen el salario de los trabajadores en violación a los convenios laborales, a los principios de irrenunciabilidad de derechos, y a lo dispuesto en el propio DNU 260 en relación a que "los trabajadores del sector privado tendrán derecho al goce íntegro de sus ingresos habituales". En ese sentido, exigieron la derogación de todas las normativas "que permitan, faciliten o promuevan la tramitación y homologación de acuerdos individuales y colectivos de suspensión y/o reducción salarial". ${ }^{112}$

Existen escasos datos globales confirmados sobre este período, aún muy cercano en el tiempo. El "Observatorio Despidos durante la Pandemia" relevó desde el 20 de marzo hasta el 25 de mayo un total de 139.364 despidos, 1.786 .878 suspensiones (incluyen casos en los que se sumaron suspensiones y recortes salariales), y 1.795.888 trabajadores/as afectados/as por rebajas salariales, aunque la metodología general y la inclusión de denuncias, cuya formade sistematización y trabajo no se clarifica en forma suficiente, hace que esta información necesite una mayor contrastación. Según señala el mismo informe, los sectores más afectados por todas estas situaciones fueron comercio, trabajadoras domésticas, gastronomía y construcción. ${ }^{113}$

Un caso emblemático que da cuenta de la continuidad de este eje de conflictividad es el de la planta alimenticia del conglomerado internacional Mondelez, ubicada en la localidad de Victoria. Allí la empresa decidió suspender a todo el personal (cerca de 550 trabajadores/as) al 75\% de su salario bruto y por el lapso de un mes, amparándose en el acuerdo firmado entre la UIA y la CGT, y a pesar de que la multinacional había estado produciendo sin problemas desde que se decretó el ASPO. El Ministerio de Trabajo homologó el "acuerdo", a pesar de

112 http://www.aal.org.ar/2020/05/18/una-reduccion-generalizada-de-los-salarios-avalada-por-elministerio-de-trabajo-de-la-nacion/

113 http://www.laizquierdadiario.com/Mas-de-3-7-millones-de-trabajadores-sufren-los-despidossuspensiones-y-ataques-al-salario 
las críticas vertidas por algunos diputados nacionales del propio oficialismo. ${ }^{114}$ Los/as delegados/as de la planta denunciaron que, a pesar de no ser consultadas las bases, las suspensiones contaron con el aval del Secretario General del Sindicato de la Alimentación, Rodolfo Daer. Este afirmó en sucesivas entrevistas que Mondelez tuvo un período de alta productividad y bajo consumo, por lo cual había acumulado mercadería que no podía colocar en el mercado, y que el cierre de la planta estaba justificado. ${ }^{115}$ Los/as delegados/as de la planta realizaron actos y aplausazos en la puerta de la fábrica, con apoyo de trabajadores/as de otros rubros, para rechazar las suspensiones y exigir el 100\% del pago de sus salarios. ${ }^{116}$ Finalmente, lograron una audiencia en el Ministerio de Trabajo en la que la empresa se comprometió a convocarlos/as nuevamente a todos/as el 15 de junio para volver a trabajar y que no habría cierre de la misma, pero también que cobrarían el $77 \%$ de los salarios, además de no cobrar los premios y la diferencia por las horas extras de los días sábados. ${ }^{117}$

El 22 de mayo tuvo solución un importante conflicto iniciado el 28/04 en relación a los 238 trabajadores/as de la minera Trident Southern Explorations, en Andacollo, provincia de Neuquén. Tras un proceso de vaciamiento del emprendimiento y distintos conflictos suscitados durante 2019, la empresa no pagó los sueldos de marzo ni abril. El 24 de abril solicitó la apertura del concurso de acreedores y el 8 de mayo el Estado rescindió el contrato de concesión de la mina. Los/as trabajadores/as reclamaron que la empresa abone los dos meses de salarios adeudados, y desarrollaron para ello distintas acciones: una toma de las instalaciones de la mina, una toma del municipio, un corte de la ruta 22 por más de dos semanas, una caravana a la capital de Neuquén y un acampe frente al Ministerio Público Fiscal de la provincia. Tras distintas audiencias de mediación y negociaciones se firmó un acuerdo entre el Sindicato Minero y el gobierno, que los representantes obreros aceptaron: se garantizó una ayuda monetaria extraordinaria, la continuidad laboral, e indemnizaciones en caso de que la nueva empresa concesionaria de la mina no absorba a todos/as los/as trabajadores/as. ${ }^{118}$

En el caso del transporte público urbano, un sector declarado como esencial desde el comienzo del ASPO, se desarrollaron importantes conflictos durante este período. Desde el mediodía del 11 de mayo la Unión Tranviaria Automotor (UTA) convocó a un paro de los servicios públicos de transporte de pasajeros en

\footnotetext{
114http://infogremiales.com.ar/noticia.php?n=62265

${ }^{115} \mathrm{https} / / /$ enfoquesindical.org/mondelez-suspende-todo-personal-planta-victoria

$116 \mathrm{http}: / /$ www.laizquierdadiario.com/Los-trabajadores-de-Mondelez-se-plantan-contra-lassuspensiones-y-rebajas-salariales

117 http://www.laizquierdadiario.com/Los-trabajadores-de-Mondelez-planta-Victoria-noshicimos-escuchar

118 https://www.anred.org/2020/05/18/neuquen-por-segunda-vez-huelga-de-mineros-y-minerasde-andacollo/; https:/www.anred.org/2020/05/22/triunfo-minero-se-firmo-el-acuerdo-con-elgobierno
} 
todas las provincias del país, a excepción de Salta, San Juan, y el AMBA. Las denuncias se relacionaron con el no cobro de salarios o su pago en cuotas, y con incumplimientos en lo referido a protocolos preventivos de higiene y seguridad. Las cámaras empresarias del transporte difundieron un comunicado de prensa alegando crisis, exigiendo subsidios y amenazando con un lockout. La conflictividad se extendió a partir de allí en diferentes provincias como Tucumán, Jujuy, Neuquén y Santa Fe.119 120121122

En el rubro siderúrgico, tras una reunión del CEO con el intendente de la localidad, trascendió en la zona y los medios de comunicación una amenaza de Acindar Villa Constitución para trasladar parte de los contratos de producción a Brasil, la cual tenía como excusa la caída de la competitividad de la producción para exportación por la escasa devaluación del peso en los últimos meses en comparación con otras monedas de la región y "los impedimentos para llevar adelante la producción por los conflictos internos que se originan con el personal". ${ }^{123} 124$ La amenaza de trasladar contratos de producción a otras plantas del grupo, que ya es crónica, esta vez fue llevada adelante por la empresa vía declaraciones públicas y llamados telefónicos personalizados a trabajadores y familiares. La presión empresaria apuntó no tanto a efectivizar la amenaza sino a avanzar con algunos objetivos como la reducción de la plantilla a través del despido de trabajadores/as suspendidos/as, el aumento de la productividad por trabajador/a en la planta, y que el Estado elimine las retenciones a las exportaciones industriales de la rama y garantice subsidios para el consumo de luz y agua. ${ }^{125}$ Por su parte, en la planta de La Matanza, la empresa continuó liquidando los salarios hasta con un $40 \%$ de quita y culpando a la organización gremial por no poder poner en marcha la planta, en castigo porque esa seccional

\footnotetext{
119 https://mundogremial.com/preocupacion-en-tucuman-la-uta-inicio-la-segunda-semana-deparo/?fbclid=IwAR1ldf6pkVDPy15Gp4QZTZ4Klk4RJOHqteA2syHZSpR1KRpOe6DQqtodTrM $120 \quad$ https://mundogremial.com/neuquen-la-uta-se-moviliza-por-problemassalariales/?fbclid=IwAR2oGvZjmkU98ofgFmTeeosdEKW10f2OCP2lyuff0kpyj1TobT-oiXILmZE $121 \quad$ https://mundogremial.com/colectiveros-jujenos-paran-en-reclamo-de-salariosadeudados/?fbclid=IwAR1mysp0TI1ZvsLk9nAgSJ_aAL_HzwSZralVm7LCEkTR0Umt0LqOK9PBzU

122 https://mundogremial.com/uta-santa-fe-desde-el-gobierno-piden-a-nacion-asistencia-con-lossalarios-para-destrabar-el-paro/?fbclid=IwAR3FMyaCsJfeN2sZsB8teEI9Pi63WfVWg61Ylaoor45ECRokgI3YxQ-Tjw ${ }^{123} \mathrm{https} / /$ puntobiz.com.ar/noticias/val/130383/val_s/44/acindar-propone-flexibilizacion-laboral-ala-uom-para-no-perder-exportaciones.html 124https://www.pagina12.com.ar/264936-acindar-quiere-cerrar-a-medias 125 https://www.elcohetealaluna.com/nunca-es-mal-momento-para-flexibilizar/; https://www.letrap.com.ar/nota/2020-5-8-15-39-0-la-amenaza-que-perotti-eligio-ver-como-unaoportunidad
} 
no avaló el acuerdo salarial firmado por la organización gremial metalúrgica a nivel nacional. ${ }^{126}$

En Dálmine-Siderca, del grupo económico Techint, el mismo día que el Poder Ejecutivo prorrogó la prohibición de despidos y suspensiones, se anunciaron despidos de trabajadores de una empresa tercerizada (Ferrúa) por una de las contratistas que procesa la chatarra en la planta (Scrapservice). ${ }^{127}$ El Ministerio de Trabajo dictó la conciliación obligatoria. ${ }^{128}$ Según fue resaltado en distintas notas, la intención de la empresa a futuro es achicar planteles de tercerizados/as vía eventuales despidos cuando termine la vigencia de los acuerdos a fin de junio. Los/as trabajadores/as propios de la fábrica principal absorberían las tareas que antes hacían los contratistas. A diferencia de lo que piden los delegados de la planta hace años, el pase a planta de tercerizados/as, la idea sería que se eliminen puestos y se adicionen tareas a los/as trabajadores/as directos, o sea, una mayor flexibilidad interna. ${ }^{129}$ El 23 de mayo se conoció que la empresa, luego de las intensas presiones que vimos desembocar en una apertura limitada de sus actividades productivas y la merma progresiva en la producción, recurrió a la estrategia del lockout, es decir, detuvo todos los procesos industriales a excepción de los "servicios ininterrumpibles", por un período que se extendería hasta el 8 de junio, cuando se retomaría una actividad reducida. La justificación de la dirección empresarial estuvo dada por la caída en las ventas derivada de la brutal contracción de la actividad petrolera en el mundo, y particularmente, en el yacimiento Vaca Muerta. La unilateral decisión empresaria reavivó el temor entre los/as trabajadores/as de que la empresa esté trasladando contratos de producción a otras de sus plantas en el mundo, así como de posibles despidos masivos en el futuro en Campana.

En el mismo momento en que salían a la luz los despidos de trabajadores/as tercerizados/as, se conocía que Techint Ingeniería y Construcción, Tenaris Siderca y Ternium Siderar percibieron subsidios entregados por el Estado vía pago de salario complementario (ATP) para cubrir hasta el 50\% del salario neto de abril, abracando incluso a gerentes, jefes de sectores y algunos de sus CEOs. ${ }^{130}$ Otras grandes empresas que mencionamos previamente involucradas en despidos y suspensiones, y en diversos conflictos laborales durante el ASPO, también fueron

\footnotetext{
126https://www.elcohetealaluna.com/se-largo-la-produccion/

127https://www.elcohetealaluna.com/se-largo-la-produccion/

${ }^{128} \mathrm{https} / /$ mundogremial.com/conciliacion-obligatoria-a-techint-por-30-trabajadores-despedidosde-tenarissiderca/?fbclid=IwAR3TW9Wn33rBH4S4vCCWgku9OFiEEwKRdFUPTuu6uwvecWtcOtBWwP MDmMI

${ }^{129} \mathrm{https}: / / \mathrm{www} . e l c o h e t e a l a l u n a . c o m / n u n c a-e s-m a l-m o m e n t o-p a r a-f l e x i b i l i z a r /$

$130 \mathrm{https} / /$ www.eldestapeweb.com/politica/crisis-economica/el-ceo-de-techint-despidio-1-450trabajadores-y-esta-anotado-para-cobrar-parte-de-su-sueldo-del-estado
} 
beneficiadas por el subsidio estatal: Latam ${ }^{131}$, Acindar ${ }^{132}$, Volkswagen ${ }^{133}$, Ledesma $^{134}$, entre otras. En el caso de la empresa de neumáticos FATE los/as trabajadores/as habían cobrado un $50 \%$ de la segunda quincena de abril y se sucedieron movilizaciones al Ministerio de Trabajo y ollas populares en la planta de San Fernando, acompañadas por el Sindicato Único de Trabajadores/as del Neumático de Argentina (SUTNA), en reclamo por el pago completo de salarios y que se incluya a los/as trabajadores/as exceptuados/as de concurrir a la planta. Las distintas acciones de protesta dieron lugar a que la empresa se comprometa a pagar los salarios adeudados, contando con el subsidio estatal del ATP. ${ }^{135} \mathrm{Al}$ mismo tiempo, las empresas recuperadas por sus trabajadores/as (muchas de las cuales mencionamos previamente que reconvirtieron sus producciones y servicios para abastecer nudos centrales de la demanda por la pandemia) y las cooperativas de trabajo quedaron afuera del beneficio estatal y de casi cualquier otra ayuda para continuar en actividad. ${ }^{136}$

Aparte de la profundización de este eje de ataque a las condiciones de vida de la clase trabajadora que evidenciamos ya desde pocos días después de decretado el ASPO, evaluamos que otra de las características centrales de este subperíodo es la reanudación progresiva de muchos sectores de la producción industrial que hasta allí no habían retornado a su trabajo ${ }^{137}$, en los que comenzaron a darse disputas por los contenidos y las formas de los protocolos de higiene y seguridad a aplicar, y las acciones ante posibles situaciones de contagio en las plantas. Estas líneas de conflictividad se profundizarían en las semanas siguientes, ya entrado el mes de junio.

En el caso de la planta de Pacheco de Volkswagen volvió a la actividad, y fue visitada por el presidente Alberto Fernández y el gobernador de la provincia de Buenos Aires Axel Kicillof. La producción se reanudó con un protocolo de prevención aprobado por el SMATA y el Ministerio de Trabajo. Concurren 1500 trabajadores, la mitad del cuerpo total de la planta, en un solo turno de seis horas. Algunas medidas adoptadas fueron la incorporación de tótems sanitizadores, cámaras para medición térmica, termómetros infrarrojos, demarcaciones de piso,

\footnotetext{
131http://www.infogremiales.com.ar/noticia.php?n=62242

${ }^{132}$ https://www.elcohetealaluna.com/nunca-es-mal-momento-para-flexibilizar/

133 https://www.telam.com.ar/notas/202005/465690-volkswagen-pago-salarios-aportes-delestado.html

${ }^{134}$ http://infogremiales.com.ar/noticia.php?n=62217

135 https://www.anred.org/2020/05/15/los-trabajadores-del-neumatico-en-fate-logran-cobrarsalario-completo; https://www.iprofesional.com/economia/316112-fate-anulo-rebaja-salrial-trasrecibir-subsidios

136https://www.anred.org/2020/04/29/el-gobierno-no-contempla-a-las-cooperativas-de-trabajo/

137 https://www.diariopopular.com.ar/general/la-industria-ya-reanudo-la-produccion-protocolos$\mathrm{n} 476184$
} 
entre otras. ${ }^{138} \mathrm{El}$ Cuerpo de Delegados de la planta planteabadudas y cuestionamientos respecto a los protocolos y las formas de desplazamientos del personal en el viaje a y desde la planta. ${ }^{139}$

Desde mediados de abril, en Tenaris SIAT Valentín Alsina la empresa venía ejerciendo diversas presiones a los/as trabajadores/as para reiniciar tareas. La comisión interna se opuso y con el apoyo de los/as operarios/as logró frenar el intento. Mientras tanto, se debatió dentro del Comité Mixto de Higiene y Seguridad un protocolo de seguridad para el retorno al trabajo. Hacia el 18 de mayo la empresa logró retornar paulatinamente a las actividades productivas, con la comisión interna dispuesta a verificar en los hechos el cumplimiento del protocolo acordado. En paralelo, continuaba el conflicto por los términos de las suspensiones aplicadas y el quite del premio por producción. ${ }^{140}$

\section{CONCLUSIONES}

Este breve análisis focalizado en los dos primeros meses de expansión de la pandemia del COVID-19 en Argentina permite iluminar, aún en un contexto de profundas restricciones para la organización y protesta colectiva, la existencia de diversas protestas y conflictos laborales, estrechamente vinculados con una serie de políticas empresariales que tuvieron como objetivo transferir, en la mayor medida posible, los costos de la crisis económica a otros sectores sociales, y especialmente, a la clase trabajadora. Aún con las complejidades metodológicas y de fuentes señaladas, y teniendo en cuenta el desafío que implica analizar un proceso que aún está en pleno desarrollo, esta breve contribución preliminar muestra a las claras que en aún en una etapa de extremas restricciones de movilidad y de profundos cambios de funcionamiento social y económico como la que tuvo lugar en el marco de las políticas de aislamiento social obligatorio existieron diversos procesos de conflictividad laboral en los que se pusieron en juego disputas centrales en torno a la "esencialidad" de distintas actividades económicas y los derechos laborales y las condiciones de vida, trabajo y organización de los trabajadores/as. Dado el recorte inicial propuesto, y el tipo de fuentes, se visibilizaron los procesos de reclamo y protesta de sectores mayoritariamente registrados y sindicalizados, pero incluso en este marco resultaron visibles procesos de organización de colectivos de trabajadores/as no registrados/as que merecen un análisis y sistematización, al igual que el abordaje de territorios, actividades y zonas no cubiertas por las fuentes utilizadas. También la pandemia ha dejado en claro la enorme trascendencia de los trabajos de

\footnotetext{
138 https://www.cronista.com/apertura-negocio/empresas/Alberto-Fernandez-y-Axel-Kicillofvisito-la-planta-de-Volkswagen-que-retomo-operaciones-20200519-0004.html

${ }^{139} \mathrm{https} / /$ www.elcohetealaluna.com/se-largo-la-produccion/

${ }^{140}$ Comunicación telefónica con José Villa, miembro de la comisión interna de Tenaris SIAT Valentín Alsina.
} 
cuidado, mayoritariamente llevados adelante por mujeres, tanto dentro como fuera de los hogares,y sean o no remunerados;lo cual hemos intentado evidenciar más allá de que la conflictividad en este eje resulta todavía difícil de mensurar.

A partir del desarrollo en los apartados previos es posible proponer una breve síntesis de algunos de los ejes centrales, que en todos los casos enfatizan la necesidad de analizar las políticas empresariales, que tuvieron una muy alta intensidad e incidencia en los diversos períodos. Los conflictos de una etapa inicial (20 de marzo a inicios de abril) se registraron fundamentalmente en relación a la necesidad de que los/as trabajadores/as pudieran cumplir con el aislamiento dictado y/o a que los esfuerzos productivos se dirigieran efectivamente a garantizar bienes y servicios esenciales para la sociedad y para aquellas actividades sanitarias orientadas a combatir la pandemia, disputando criterios sobre qué es esencial y qué no en este contexto. Esa conflictividad derivó, en muchos casos en los que no se logró evitar concurrir al trabajo o reconvertir la producción, en la exigencia de las debidas condiciones de higiene y seguridad en el trabajo que permitieran una efectiva protección en el marco de la pandemia. Una gran parte de estos conflictos fueron motorizados por trabajadores/as y niveles de organización sindicalde base.

Rápidamente, sin embargo, las coordenadas del conflicto cambiaron. Un punto claro de inflexión fue el despido de 1450 trabajadores/as de la construcción por parte del grupo económico Techint, el 28 de marzo, a partir de lo cual la conflictividad laboral estuvo centrada en el intento de limitar o repeler recortes salariales, suspensiones y despidos. Una vez sancionado el Decreto 329/20, que intentó contener los despidos, las dirigencias empresariales delinearon nuevas estrategias para hacer descargar la crisis sobre los/as trabajadores/as, registrándose un salto cualitativo en la conflictividad por trabajadores/as afectados/as por despidos, suspensiones y rebajas salariales.

Hacia mediados de abril diversas dirigencias de las organizaciones sindicales por rama de actividad de base nacional tuvieron mayor participación, y se sucedieron acuerdos de suspensiones con rebajas salariales, algunos de los cuales fueron puestos en cuestión por seccionales y organizaciones de trabajadores/as de base. Continuaron asimismo las disputas por el cumplimiento de medidas de salubridad efectivas para prevenir contagios y los reclamos relacionados con el accionar empresario frente a la presencia de casos de COVID-19 en la plantilla de trabajadores/as. También se verificaron distintos reclamos en relación a los sectores trabajando con modalidades de teletrabajo, exigiendo una mayor regulación y acuerdos precisos sobre sus formas de aplicación para garantizar derechos fundamentales en cada una de las actividades.

Una de las particularidades del cuarto período, ya hacia principios de mayo, fue que, a partir del aumento exponencial de contagios en las villas de emergencia y los barrios populares, se puso de relevancia cómo la crisis intensificó tareas de cuidado que, llevadas adelante centralmente por mujeres y disidencias, 
habitualmente invisibilizadas y que en el marco de la pandemia se evidencian claramente como fundamentales para la reproducción de la vida. La protesta desde los barrios y villas aumentó fuertemente, a través de canales que no son las habitualmente utilizados para medir conflictividad laboral, y centralmente en relación al pedido de alimentos para los barrios y asignaciones para los/as trabajadores/as no registrados. Durante los primeros días de mayo, y a partir del acuerdo firmado por la CGT y la UIA, se dio una generalización de la negociación colectiva entre cámaras empresariales y sindicatos por rama que implicaron en numerosos casos la aplicación de suspensiones y rebajas salariales avaladas por el Ministerio de Trabajo,lo que sin embargo no hizo que la conflictividad desde seccionales y lugares de trabajo desaparezca. Al mismo tiempo, sin embargo, existieron procesos de negociación que pudieron lograr no sólo frenar los intentos de rebaja salarial, sino incluso garantizar incrementos salariales.

Un último período, del 11 al 25 de mayo, estuvo definido por una continuidad de despidos, suspensiones y rebajas salariales en diversos casos, pero además incluyó formas más extremas de condicionamiento empresarial, como el anuncio de posible relocalización de la producción o por la aplicación de medidas de lockout patronal, así como otras formas de presión para que distintas ramas de la economía y establecimientos volvieran a la actividad aún con riesgos. Con la continuidad de la reapertura de actividades, es posible suponer que se dará una disputa creciente en relación a los protocolos de higiene y seguridad a aplicar en cada espacio laboral, así como respecto a las acciones a tomar en casos del aumento de contagios en espacios de trabajo. En este contexto, partir de un balance de las etapas anteriores de esta disputa podría resultar importante para habilitar nuevas formas de acción sindical y laboral que permitan garantizar la defensa de los puestos de trabajo, pero garantizando además derechos laborales, niveles salariales y condiciones de trabajo en un contexto mundial y regional en el que se están verificando muy significativos retrocesos en todos estos campos.

\section{BIBLIOGRAFÍA}

Arias, Cora, Bonnin, Juan, Bulloni, María, Del Bono, Andrea, Di Giovambattista, Ana, Gárriz, Ana, Haidar, Julieta. Natalucci, Ana y Vocos, Federico, "Trabajo en cuarentena. Encuesta realizada en el marco del proyecto Monitor Laboral COVID19", CITRA-UMET, Julio 2020.

Basta de Asesinatos Laborales, relevamiento "Condiciones de trabajo y prevención COVID-19", 19 de abril de 2020. Disponible en: https://www.facebook.com/bastadeasesinatoslaborales/posts/2539616949688364 
Basta de Asesinatos Laborales, Placas, 21 y 28 de marzo de 2020. Disponibles en: https://www.facebook.com/bastadeasesinatoslaborales/posts/2513349292315130htt ps://www.facebook.com/bastadeasesinatoslaborales/posts/2520017568314969

Basualdo, Eduardo (editor), Barrera, Mariano, Bona, Leandro, González, Mariana, Manzanelli, Pablo y Wainer, Andrés, Endeudar y fugar. Un análisis de la historia económica argentina de Martínez de Hoz a Macri, Buenos Aires: Siglo Veintiuno editores, 2020, Edición ampliada.

Basualdo, Eduardo M., Manzanelli, Pablo y Calvo, Daniela, “Un balance preliminar de la crisis económica en la Argentina en el marco del coronavirus", CIFRA-CTA y AEyT de FLACSO, Junio de 2020.

Basualdo, Victoria, "Los intentos de Reforma Laboral regresiva en la Argentina desde 2015: una lectura en perspectiva histórica" en ClariceGontarskiSperanza (coord.), História do Trabalho: entre debates, caminhos e encruzilhadas, Brasil, Paco Editorial, 2020. Disponible en: https://lehmt.org/2020/05/23/livro-historia-dotrabalho-entre-debates-caminhos-e-encruzilhadas-download-gratuito/

Basualdo, Victoria (coord.), Hernán Letcher, Silvia Nassif, Mariano Barrera, Nayla Bosch, Andrea Copani, Pablo Peláez, Mauro Rojas, "Cambio tecnológico, tercerización laboral e impactos sobre el empleo. Desafíos desde y para una narrativa argentina", Buenos Aires: Fundación Friedrich Ebert, Marzo 2019. Disponible en: https://www.fes-argentina.org/

Basualdo, Victoria, Esponda, María Alejandra, Gianibelli, Guillermo y Morales, Diego, Tercerización y derechos laborales en la Argentina actual, Universidad Nacional de Quilmes-Página 12, 2015.

Basualdo, Victoria y Morales, Diego (coords.), La tercerización laboral: orígenes, impactos y claves para su análisis en América Latina, Buenos Aires, Editorial Siglo Veintiuno, 2014.

- Centro de Economía Política Argentina (CEPA), Informe “El impacto del aislamiento en el mercado de trabajo", 20 de abril de 2020. Disponible en: https://www.centrocepa.com.ar/informes/249-el-impacto-del-aislamiento-en-elmercado-de-trabajo-cuantificacion-de-despidos-suspensiones-y-reduccionessalariales-entre-el-15-de-marzo-y-el-15-de-abril.html 
CETyD-UNSAM, "Políticas Sociolaborales en tiempos del COVID-19. Cobertura y desafíos futuros", 2 de junio de 2020. Disponible en:

http://noticias.unsam.edu.ar/wp-content/uploads/2020/06/CETyD-Politicassociolaborales-en-tiempos-de-Covid19.pdf

CIFRA-CTA, "El incremento en las tarifas de servicios públicos y su peso sobre los salarios", enero 2019, disponible en:

http://www.centrocifra.org.ar/publicacion.php?pid=137.

CIFRA-CTA, Informe "Medidas socioeconómicas ante la crisis provocada por el Coronavirus", Abril 2020. Disponible en: http://www.centrocifra.org.ar/

CIFRA-CTA, "Trabajo, sindicatos y Estado en la crisis generada por el COVID19", Mayo de 2020. Disponible en:

http://www.centrocifra.org.ar/docs/Trabajo\%20sindicatos\%20y\%20Estado\%20en $\% 201$ \%20crisis.pdf

Comisión de Ciencias Sociales de la Unidad Coronavirus COVID-19, "Relevamiento del impacto social de las medidas del Aislamiento dispuestas por el PEN", abril de 2020.

Equipo COVID-19 en la Región Sanitaria VI, Instituto Gino Germani (Facultad de Ciencias Sociales, UBA), Tercer reporte "Trabajadores de la región sanitaria VI en el contexto del Covid 19". Disponible en:

https://medium.com/@Covid19RegionSanitariaVI/tercer-reporte-be679da4d30a

Equipo de Estudio sobre sindicalismo, conflicto y territorio, Informe "La situación del empleo en Argentina durante el aislamiento social, preventivo y obligatorio por la pandemia COVID-19", del 11 de mayo de 2020. Disponible en: http://www.ceil-conicet.gov.ar/2020/05/informe-la-situacion-del-empleo-enargentina-durante-el-aislamiento-social-preventivo-y-obligatorio/informe-ceil-elempleo-en-la-argentina-en-el-marco-del-aspo/

Ernst,Christoph y López Mourelo, Elva, “La COVID-19 y el mundo del trabajo en Argentina: impacto y respuestas de política", OIT, 20 de abril de 2020. Disponible en: https://www.ilo.org/wcmsp5/groups/public/---americas/---ro-lima/---ilobuenos_aires/documents/publication/wcms_740742.pdf 
IDESBA-SUTEBA, “Primera presentación de resultados de la Encuesta Provincial de Trabajo Docente en contexto de Aislamiento Obligatorio", 25 de junio de 2020. Disponible en: https://www.suteba.org.ar/download/encuesta-provincial-detrabajo-docente-en-contexto-de-aislamiento-se-presentaron-los-resultados84841.pdf

López Mourelo, Elva, “La COVID-19 y el trabajo doméstico en Argentina”, OIT, 20 de abril de 2020.

Ministerio de Trabajo de la Nación Argentina, Informe "Situación y evolución del trabajo registrado", 5 de junio de 2020

http://www.trabajo.gob.ar/downloads/estadisticas/reportelaboral/Reporte_Labora 1_Junio_2020.pdf

Ministerio de Trabajo de la Nación, Informe “Empleo registrado del sector privado a partir de los datos de la Encuesta de Indicadores Laborales para Mayo de 2020", Julio de 2020. Disponible en:http://www.trabajo.gob.ar/downloads/estadisticas/eil/eil_2005_informe.pdf

Naciones Unidas, "TheImpact of COVID-19 onWomen”, 9 de abril de 2020. Disponible en: https://www.unwomen.org//media/headquarters/attachments/sections/library/publications/2020/policy-briefthe-impact-of-covid-19-on-women-en.pdf?la=en\&vs=5029

Observatorio del Derecho Social de la CTA Autónoma, Informe "El trabajo en el marco de la emergencia sanitaria. Propuestas urgentes para la cuarentena", 30 de marzo de 2020. Disponible en: http://ods.ctaautonoma.org.ar/2020/03/30/eltrabajo-en-el-marco-de-la-emergencia-sanitaria/

Observatorio del Derecho Social de la CTA Autónoma. Informe "El trabajo en la cuarentena. Evaluación del estado de las relaciones laborales a un mes de dictado el aislamiento, social, preventivo y obligatorio", 28 de abril de 2020. Disponible en: https://www.agenciacta.org/IMG/pdf/El_trabajo_en_la_cuarentena__Informe_ODS_CTAA_28_de_abril.pdf

Observatorio del Derecho Social de la CTA Autónoma, Informe "Negociación colectiva 2020: revisiones, aumentos y suspensiones", 24 de julio de 2020.

Disponible en: http://ods.ctaautonoma.org.ar/wpcontent/uploads/2020/07/Negociaci\%C3\%B3n-colectiva-2020-Primer-semestre.pdf 
Oficina de Violencia de Género de la Suprema Corte de Justicia de la Nación, "Informe sobre las presentaciones en OVD durante el período de aislamiento social, preventivo y obligatorio", Julio 2020.

Organización Internacional del Trabajo (OIT), “El COVID-19 y el mundo del trabajo: Repercusiones y respuestas",18 de marzo de 2020. Disponible en: https://www.ilo.org/wcmsp5/groups/public/---dgreports/--dcomm/documents/briefingnote/wcms_739158.pdf

Organización Internacional del Trabajo (OIT), “Las normas de la OIT y el COVID-19 (coronavirus)",29 de mayo de 2020, Versión 2.1, disponible en: https://www.ilo.org/wcmsp5/groups/public/---ed_norm/--normes/documents/publication/wcms_739939.pdf

San Juan, Claudio, "Estudio comparado de la legislación sobre Teletrabajo en los países de América Latina y el Caribe", Junio de 2020, disponible en: https://redsstalc.blogspot.com/2020/07/larga-vida-al-teletrabajo.html 